\title{
PROPOSTA DE ÍNDICE BIDIMENSIONAL DE TRANSPARÊNCIA DA INFORMAÇÃO PÚBLICO-ELETRÔNICA COMO FERRAMENTA PARA PARTICIPAÇÃO E CONTROLE SOCIAIS ${ }^{1}$
}

\author{
Douglas Arrais Melo \\ Hélio Yochihiro Fuchigami ${ }^{3}$
}

http://dx.doi.org/10.1590/1413-2311.248.91523

\section{RESUMO}

A Lei de Acesso à Informação (LAI) representa a reafirmação da transparência como um componente-chave à credibilidade e efetividade das ações do Estado. Assim, se as informações em sítios público-eletrônicos estão indisponíveis, incompletas e/ou incompreensíveis, elas podem comprometer o cumprimento factual da LAI e a promoção de transparência. O objetivo principal deste estudo foi desenvolver um índice bidimensional de transparência orientado aos sítios eletrônicos das universidades federais a partir da avaliação da qualidade de sua informação. Esse índice possui enfoque na informação como "produto", com atributos determinados por uma abordagem mormente intuitivo-teórica. Os principais resultados identificaram: sítios mais e menos transparentes e benchmarks. O índice possibilitou verificar, com alta precisão, a qualidade da informação dos sítios, a qual se apresentou pouco transparente, insuficiente para a devida compreensão pelo cidadão. Isso aparentou indicar pouco engajamento tanto de agentes públicos para cumprir a lei quanto de stakeholders para exercer controle social. Junto a um confiável índice de transparência,

\footnotetext{
${ }^{1}$ Recebido em 01/04/2019; aprovado em 02/07/2019.

${ }^{2}$ Universidade Federal de Goiás - Instituto de Física; Goiânia - GO (Brasil) - http://orcid.org/0000-0001-96892530. E-mail: arrais.melo@gmail.com.

${ }^{3}$ Universidade Federal de Goiás - Faculdade de Ciências e Tecnologia; Aparecida de Goiânia - GO (Brasil) http://orcid.org/0000-0002-8943-1506. E-mail: heliofuchigami@yahoo.com.br.
} 
conscientização, união e atuação sociais em prol da transparência são fundamentais à evolução da participação e do controle sociais.

Palavras-chave: Lei de Acesso à Informação. Qualidade da informação pública. Transparência ativa.

\title{
PROPOSAL FOR A TWO-DIMENSIONAL INDEX OF TRANSPARENCY OF PUBLIC-ELECTRONIC INFORMATION AS A TOOL FOR SOCIAL PARTICIPATION AND SOCIAL CONTROL
}

\begin{abstract}
The Law on Access to Information (LAI) represents the reaffirmation of transparency as a key component of the credibility and effectiveness of State actions. Thus, if the informations on public-electronic sites are unavailable, incomplete and/or incomprehensible, it may compromise the factual compliance of the LAI and the promotion of transparency. The main objective of this study was to develop a two-dimensional index of transparency oriented to the electronic sites of the federal universities based on the evaluation of the quality of their information. This index has a focus on information as a "product", with attributes determined by a mostly intuitive-theoretical approach. The main results identified: more and less transparent sites and benchmarks. The index made it possible to verify, with high precision, the quality of the information of the sites, which was not very transparent, insufficient for the proper understanding by the citizen. This appeared to indicate little involvement by both public officials to comply with the law and stakeholders to exercise social control. Along with a reliable index of transparency, awareness, union and social action for transparency are fundamental to the evolution of social participation and social control.
\end{abstract}

Keywords: Law on Access to Information. Quality of public information. Active transparency.

\author{
PROPUESTA DE ÍNDICE BIDIMENSIONAL DE TRANSPARENCIA DE LA \\ INFORMACIÓN PÚBLICA-ELECTRÓNICA COMO HERRAMIENTA PARA \\ PARTICIPACIÓN Y CONTROL SOCIALES
}

REAd | Porto Alegre - Vol. 25 - No 2 - Maio / Agosto 2019 - p. 179-214 


\section{RESUMEN}

La Ley de Acceso a la Información (LAI) representa la reafirmación de la transparencia como un componente clave a la credibilidad y efectividad de las acciones del Estado. Así, si las informaciones en sitios público-electrónicos están indisponibles, incompletas y/o incomprensibles, ellas pueden comprometer el cumplimiento factual de la LAI y la promoción de transparencia. El objetivo principal de este estudio fue desarrollar un índice bidimensional de transparencia orientado a los sitios electrónicos de las universidades federales a partir de la evaluación de la calidad de su información. Este índice tiene foco en la información como "producto", con atributos determinados por un enfoque mayormente intuitivo-teórico. Los principales resultados identificaron: sitios más y menos transparentes y benchmarks. El índice posibilitó verificar, con alta precisión, la calidad de la información de los sitios, la cual se presentó poco transparente, insuficiente para la debida comprensión por el ciudadano. Esto pareció indicar poco compromiso tanto de agentes públicos para cumplir la ley y de stakeholders para ejercer control social. Junto a un confiable índice de transparencia, concientización, unión y actuación sociales en favor de la transparencia son fundamentales para la evolución de la participación y del control sociales.

Palabras clave: Ley de Acceso a la Información. Calidad de la información pública. Transparencia activa.

\section{INTRODUÇÃO}

Nas últimas décadas, o surgimento de modelos de gestão com ênfase no controle de resultados; a evolução das Tecnologias da Informação e Comunicação (TIC) - Internet aliada a sistemas, aplicativos e sítios eletrônicos - e sua inserção-transformação na vida cotidiana dos indivíduos; e as diversas e contingentes demandas sociais elevaram o nível de complexidade do setor público e, por conseguinte, seu volume de informações.

Em consonância ao atual momento da Administração Pública (AP) - voltado à gestão social - e a seus princípios constitucionais da "publicidade" e "eficiência", a gestão (transparente) da informação pública se colocou como aspecto fundamental à ciência e 
compreensão das ações do Estado pelo cidadão e, em vista disso, à consecução da participação e do controle sociais (BITENCOURT; RECK, 2016; BRASIL, 1988).

O acesso à informação pública no País, todavia, é bastante recente, oficializado mediante Lei $\mathrm{n}^{\mathrm{o}}$ 12.527, de 18 de novembro de 2011, conhecida como "Lei de Acesso à Informação" (LAI), que estabeleceu a instituições públicas a obrigatoriedade de divulgação de suas informações por meio de sítio eletrônico oficial ("transparência ativa") e do Serviço de Informação ao Cidadão (SIC) ("transparência passiva”) (BRASIL, 2011).

Desde a instituição da LAI, observa-se, por meio dos relatórios estatísticos do SIC relativos às instituições públicas do Poder Executivo Federal (PEF), que o cidadão tem pedido, com considerável frequência, acesso à informação pública, ratificando-se, em teoria, o controle das ações do Estado pela sociedade; o que, por outro lado, também pode pressupor uma insuficiência de informações nos sítios eletrônicos dessas instituições (BRASIL, 2018a).

Além disso, apesar das orientações do Guia de Transparência Ativa para Órgãos e Entidades do Poder Executivo Federal (BRASIL, 2017a) e do Modelo de Acessibilidade em Governo Eletrônico (e-MAG) (BRASIL, 2014), instrumentos oficiais do Ministério da Transparência e Controladoria-Geral da União - CGU (principal órgão de controle do governo federal voltado à defesa do patrimônio público e ao incremento da transparência pública) e do governo federal respectivamente, muitas das informações nesses sítios podem estar indisponíveis, incompletas e/ou incompreensíveis, indo de encontro ao que propõe a LAI (BRASIL, 2011, art. 5, grifo nosso): "É dever do Estado garantir o direito de acesso à informação [...] de forma transparente, clara e em linguagem de fácil compreensão."

Nesse raciocínio, presumindo-se que a busca pela informação pública se inicia por meio da "transparência ativa" e dado que o indicador de transparência utilizado pelo CGU é predominantemente voltado à "transparência passiva" (a Escala Brasil Transparente - EBT) (BRASIL, 2018b), torna-se primordial mensurar a "qualidade" de toda a informação (básica e complementar) disponível nos sítios do PEF, a fim de se reafirmar o real e principal propósito da LAI: promoção de "transparência" para a participação e o controle sociais (BRASIL, 2011).

Como objetos deste estudo, foram escolhidos os sítios eletrônicos de universidades federais do Brasil em virtude do grande fluxo de informações destas, representado principalmente pelo alto número de servidores públicos ativos e de discentes matriculados e pelo vasto rol de atividades (ensino, pesquisa e extensão) (BRASIL, 2016).

Dada à necessidade de se gerir e se publicizar eficientemente esse conjunto de informações, em busca de transparência para a participação e o controle sociais, este estudo 
apresenta, portanto, o seguinte problema de pesquisa: com base na LAI, como se mensurar a qualidade da informação disponível nos sítios eletrônicos de universidades federais do Brasil?

Para se responder à pergunta-problema, estabelece-se, como objetivo deste estudo, desenvolver o Índice Bidimensional de Transparência da Informação Público-Eletrônica (IBTIPE) com as finalidades de se: mensurar os níveis de cumprimento factual da LAI e de transparência das informações complementar e total relativos aos sítios eletrônicos de universidades federais do Brasil; e elaborar rankings referentes a esses níveis.

Este artigo é composto pelas seguintes seções: 1) Referencial Teórico (informação pública, gestão pública e transparência; apresentação da LAI; transparência ativa; qualidade da informação pública; estudos afins); 2) Metodologia de Pesquisa; 3) Apresentação do IBTIPE; 4) Resultados; e as Considerações Finais.

\section{REFERENCIAL TEÓRICO}

\subsection{INFORMAÇÃO PÚBLICA E GESTÃO PÚBLICA COM TRANSPARÊNCIA NO BRASIL}

Numa noção geral, compreende-se a "informação pública" no Brasil como o conjunto de todos os dados (tratados ou não) e de documentos (unidades de registro de informações) produzidos ou geridos pela AP que sejam de interesse da sociedade, excetuando-se os restritos (reservado, secreto, ultrassecreto, sigiloso e pessoal) (BITENCOURT; RECK, 2016).

Relacionar "informação pública" a "transparência" traz à tona uma oposição cultural e histórica ao termo "corrupção", entendido, neste contexto, como corrompimento da fé pública de um agente público a fim de se obterem vantagens individuais ou para terceiros; portanto um exemplo de contravalor social (ROSA; BERNARDO; VICENTE; PETRI, 2016).

A relação entre "transparência" e "corrupção" pode ser observada a partir da fase patrimonialista da AP brasileira, em que a informação pública era restrita e concentrada nos interesses privados, ou seja, com pouca transparência pública, situação que favorecia a corrupção e, logo, o descrédito no Estado (ROSA et al., 2016).

Posto isso, uma das peças-chave para se combater a corrupção e se realizar uma boa gestão pública no País é a "transparência" - processo realçado doravante na Constituição de 1988 - que deve corresponder a um conjunto de práticas contínuas que assegurem a divulgação relevante e compreensível da informação pública e permitam a (re)avaliação de 
credibilidade no Estado pela sociedade (PLATT NETO; CRUZ; ENSSLIN; ENSSLIN, 2007).

Nesse pensamento, uma gestão pública com transparência assume responsabilidade para com os bens e os recursos públicos e, está subordinada a prestação de justificativas e sujeita a penalidades. Ao mesmo tempo, essa gestão deve criar mecanismos que possibilitem uma ativa "participação social" no (re)planejamento (tomada de decisão) do Estado, desde o debate sobre questões sociais relevantes até a (re)definição e (re)implementação de políticas públicas. Essa relação bilateral está relacionada à prática de accountability, que reúne a divulgação transparente das informações públicas, a prestação de contas e a responsabilização dos agentes públicos (AKUTSU; PINHO, 2002; CLÈVE; FRANZONI, 2013).

Atrelado à "participação social" está o conceito de "controle social". Se o propósito do Estado é a regulação das demandas sociais em busca de equidade e do bem comum; o cidadão, como maior afetado pelas ações estatais, é o ator mais indicado ao papel de "fiscalizar" tudo que pertence ou se refere à coletividade e monitorar a qualidade do serviço público. Nesse processo, quanto maior a transparência pública, maior a possibilidade de eficácia do controle social sobre o Estado e maior a eficiência no gerenciamento dos gastos públicos, ou seja, maior a possibilidade de efetividade das políticas públicas (ROSA et al., 2016).

Dessa maneira, é factível considerar que toda informação pública é um bem público, e, como tal, sua transparência configura-se num dos elementos primordiais à consecução e consolidação da "democracia", na medida em que um cidadão ciente das ações da AP e consciente de seus direitos e deveres se credencia a participar efetivamente de decisões de interesse social e a exercer o devido controle social sobre as ações do Estado (AKUTSU; PINHO, 2002; BITENCOURT; RECK, 2016).

\subsection{LEI DE ACESSO À INFORMAÇÃO (LAI)}

O acesso à informação pública do Brasil foi instituído por meio da LAI (BRASIL, 2011) - embasado em tratados e declarações internacionais (BRASIL, 1992, 2006; ORGANIZAÇÃO DAS NAÇÕES UNIDAS, 2009; ORGANIZAÇÃO DOS ESTADOS AMERICANOS, 2000); em leis como a Lei de Arquivos (BRASIL, 1991), a Lei ${ }^{\circ}$ 9.755/1998 (BRASIL, 1998), a LRF (BRASIL, 2000) e a Lei da Transparência (BRASIL, 2009); e no princípio constitucional da "publicidade" da AP - e materializou um direito previsto pela Constituição Federal (BRASIL, 1988). 
Em vigor efetivo desde maio de 2012, a LAI surgiu para promover a transparência da AP para a participação e o controle sociais enquanto exercícios de cidadania, buscando se alinhar a uma conjuntura composta: pela premissa da incerteza; pela crise político-econômica dos últimos anos; pelo societalismo; pelo avanço contínuo das TIC; pelo combate à corrupção; pelos direitos universal e constitucional à informação pública; e pela alta produção de informação pública (ABDALA; TORRES, 2016).

Dessa forma, a LAI estabeleceu: a "transparência ativa" (regulamentação do art. $5^{\circ}$, inc. XIV da Constituição), segundo a qual essas instituições devem publicizar suas informações públicas básicas e complementares em seus sítios eletrônicos; e a "transparência passiva" (regulamentação do art. $5^{\circ}$, inc. XXXIII da Constituição), que possibilita ao cidadão o direito de requerer, formalmente, acesso (sem apresentação de motivo) a qualquer outra informação pública (indisponível, incompleta ou incompreensível nos sítios) por meio do SIC (físico ou eletrônico) (BRASIL, 1988, 2011; SILVA; EIRÃO; CAVALCANTE, 2013).

A LAI representa, portanto, a renovação de culturas da AP e da sociedade e o aprimoramento da democracia quanto à prestação de contas e à comunicação entre Estado e sociedade civil e apresenta-se como o marco regulatório da publicização da informação pública como regra e de seu sigilo como exceção (ALBUQUERQUE; SILVA; SOUSA, 2017).

\section{3 “TRANSPARÊNCIA ATIVA” ORIENTADA AO PODER EXECUTIVO FEDERAL (PEF)}

Para instituições públicas do PEF (exceto para municípios com até 10 mil habitantes), a "transparência ativa" da LAI representa, em termos gerais, a obrigatoriedade de publicização de informações públicas fundamentalmente por seus sítios eletrônicos oficiais, devendo ser efetivada especificamente na seção (link) “Acesso à Informação" (BRASIL, 2012).

Essa publicização deve estar alinhada a normas tecnológico-estruturais, que obrigam os sítios eletrônicos do PEF a exporem: banner (link) intitulado "Acesso à Informação" (logomarca oficial) no sítio eletrônico principal de uma determinada instituição pública, que redireciona à seção que contém suas informações básicas; e a barra de identidade do governo federal, que deve conter, entre outros, links de redirecionamento ao sítio do governo do Brasil e ao sítio principal da LAI (BRASIL, 2012). 
Em complemento a isso, o Decreto $n^{0} 7.724 / 2012$ estabelece que os sítios eletrônicos do PEF ainda devem apresentar: 1) formulário para solicitar informação; 2) ferramenta de pesquisa de conteúdo; 3) ferramenta de gravação de relatórios em formatos como planilha e texto; 4) acesso a dados abertos (de livre utilização, reutilização e distribuição); 5) divulgação detalhada dos formatos utilizados para estruturação da informação; 6) garantia de qualidade de informações com atualização, autenticidade (informação produzida, expedida, recebida ou modificada por determinado indivíduo, equipamento ou sistema), disponibilidade (informação pública acessível), integridade (informação não modificada, inclusive quanto à origem, trânsito e destino) e primariedade (informação coletada na fonte, com máximo detalhamento e sem modificações); 7) instruções ao requerente para comunicação eletrônica ou telefônica; e, 8) acessibilidade de conteúdo para pessoas portadoras de deficiência física (BRASIL, 2012).

Numa interpretação mais precisa da LAI, a obrigatoriedade da lei refere-se à publicização mínima de informações públicas consideradas básicas (as importantes e essenciais no contexto de transparência da AP) e à publicização máxima de informações públicas complementares (as importantes, mas não essenciais, e as menos importantes no contexto de transparência da AP) (BRASIL, 2011; 2012).

Assim, a LAI, ao delimitar um mínimo de informações básicas a serem publicizadas, realça a imposição de uma "atividade", com requisitos definidos (objetivos) a serem alcançados por esses sítios, representando, portanto, uma “obrigatoriedade factual".

Por outro lado, a publicização máxima de informações complementares, ainda que reafirme a busca por transparência, representa um "gargalo" da lei, pois é uma obrigatoriedade dependente da "proatividade" e interpretação (de quais informações complementares são relevantes para disponibilização) pelas instituições públicas. Nesse sentido, por não haver um padrão de especificação de informações, não há como se atestar o cumprimento "de fato" deste ponto, logo sendo denominado, aqui, uma "obrigatoriedade não factual".

Em vista do exposto, o cumprimento da "transparência ativa" da LAI pelo PEF está associado, na prática, à “obrigatoriedade factual”, fato que torna a informação básica mais relevante que a complementar. A interpretação desses principais pontos da LAI pode ser visualizada resumidamente, mediante Quadro 1. 


\section{Quadro 1 - Transparência dos sítios eletrônicos do Poder Executivo Federal (PEF)}

\begin{tabular}{|c|c|c|c|c|c|}
\hline \multicolumn{2}{|c|}{ Dimensão } & Obrigatoriedade & Informação & $\begin{array}{c}\text { Característica da } \\
\text { informação }\end{array}$ & Publicização \\
\hline \multirow{2}{*}{$\begin{array}{c}\text { Transparên- } \\
\text { cia global } \\
\text { dos sítios } \\
\text { eletrônicos } \\
\text { do PEF }\end{array}$} & $\begin{array}{c}\text { Transparência } \\
\text { ativa }\end{array}$ & Factual & Básica & $\begin{array}{c}\text { Importante e essencial } \\
\text { pela LAI }\end{array}$ & $\begin{array}{c}\text { Mínima } \\
\text { (com } \\
\text { requisitos) }\end{array}$ \\
\cline { 2 - 5 } & $\begin{array}{c}\text { Transparência } \\
\text { proativa }\end{array}$ & Não factual & Complementar & $\begin{array}{c}\text { Importante, mas não } \\
\text { essencial pela LAI }\end{array}$ & $\begin{array}{c}\text { Máxima } \\
\text { (sem } \\
\end{array}$ \\
\end{tabular}

Fonte: elaborado pelo autor com base em Brasil $(2011,2012)$ e Silva e Carreiro (2013).

Quanto à publicização mínima de informação pública, a LAI (complementada por outras legislações afins) estabelece um rol de informações básicas com conteúdo orientado pelo Guia de Transparência Ativa para Órgãos e Entidades do Poder Executivo Federal (BRASIL, 2017a) e pelo Modelo de Acessibilidade em Governo Eletrônico (BRASIL, 2014), instrumentos oficiais do CGU e do governo federal brasileiro respectivamente.

\subsection{QUALIDADE DA INFORMAÇÃO}

A "transparência" no âmbito da AP, normalmente associada à divulgação de informações públicas, efetiva-se a partir de duas condições intercomplementares: a visibility (visibilidade da informação, ou seja, sua integridade e facilidade/probabilidade de localização) e a inferability (capacidade de entendimento - "inferência" - gerado por uma informação). Nesse sentido, a transparência de uma informação está condicionada a sua divulgação de forma completa e compreensível. Logo, quanto maiores a visibility e a inferability de uma informação, maior será sua transparência (MICHENER; BERSCH, 2011).

Percebe-se, assim, que essas duas condições estão diretamente vinculadas à "qualidade da informação", expressão normalmente relacionada à identificação de atributos (ou valores), porém sua conceituação ainda é considerada abstrata e ambígua em razão da multidimensionalidade destes (NEHMY; PAIM, 1998), tal qual expõe o Quadro 2. 


\section{Quadro 2 - Dimensões e atributos de informação}

\begin{tabular}{|c|c|}
\hline Dimensões & Atributos \\
\hline Abrangência / escopo & Vetores da informação \\
\hline Acurácia / veracidade & Nível de acurácia; e método para determinação do nível de acurácia \\
\hline Atualidade* / temporalidade & $\begin{array}{c}\text { Data de geração da informação; horário de geração da informação; e intervalo de } \\
\text { tempo entre cada nova geração de informação }\end{array}$ \\
\hline Audiência & Frequência de acesso; e duração de tempo de acesso \\
\hline Confiabilidade & Credibilidade da fonte; e credibilidade do conteúdo \\
\hline Confidencialidade / privacidade & Público-alvo; e predileções informacionais do público-alvo \\
\hline Contextualização & Caracterização da informação \\
\hline Disponibilidade* & $\begin{array}{l}\text { Meio de acesso à informação; horário de disponibilização da informação; e tempo } \\
\text { decorrido entre a solicitação e o acesso da informação }\end{array}$ \\
\hline Existência & $\begin{array}{l}\text { Localização do algoritmo para geração da informação e localização do armazenamento } \\
\text { do conteúdo informacional }\end{array}$ \\
\hline Identidade (autenticidade*) & Nome; sinônimos; e autoria \\
\hline Ineditismo / raridade & Disponibilidade de informações idênticas ou similares \\
\hline Integridade* & Nível de integridade da informação \\
\hline Originalidade (primariedade*) & Originalidade da informação \\
\hline Pertinência / agregação de valor & Valor potencial da informação e valor entregue pela informação \\
\hline Precisão & Nível de precisão da informação \\
\hline
\end{tabular}

*Dimensões exigidas pela LAI.

Fonte: Brasil (2011) e Valente e Fujino (2016).

Esses atributos têm sido situados pelos principais teóricos da área sob as duas mais usuais linhas de pensamento, que têm foco no: "usuário" ou "produto". O primeiro foco ("usuário") exalta atributos de subjetividade relacionados a: acurácia; e pertinência/agregação de valor. Esta visão é considerada limitante e intangível, dado que as preferências do usuário são variadas, contingenciais e nem sempre bem-definidas, e, logo, com pouca possibilidade de operacionalização (CALAZANS, 2008). 
Em contrapartida, o segundo foco "produto" remete às características físicas intrínsecas à própria informação (de dados, documentos e textos por exemplo), realçando uma natureza objetiva de atributos relacionados a: abrangência / escopo; atualidade/temporalidade; audiência; confiabilidade; confidencialidade; contextualização; disponibilidade; existência; identidade (autenticidade); ineditismo/raridade; integridade; originalidade (primariedade); e precisão. Nesta visão, a qualidade da informação destaca-se por sua tangibilidade, configurando-se na possibilidade de quantificar a compreensão de uma mensagem entre emissor e receptor, ou seja, na possibilidade de efetiva mensuração dos atributos da informação (NEHMY; PAIM, 1998).

A determinação dos atributos de qualidade da informação pode ocorrer a partir de três tipos de abordagens: 1) "intuitiva" - baseada em expertise e intuição; 2) "empírica" - baseada na visão do usuário; e, 3) "teórica" - baseada em atributos derivados de teorias já estabelecidas (CALAZANS, 2008).

\subsection{QUALIDADE DA INFORMAÇÃO PÚBLICA: ESTUDOS COM BASE NA LAI}

Apesar de regulamentado pela LAI somente há seis (6) anos, o "acesso à informação" já tem suscitado a produção de alguns estudos que atrelam o nível de transparência pública à qualidade da informação pública disponível em sítios público-eletrônicos.

Dos estudos pesquisados até dezembro de 2018 que se enquadram nessa linha e possuem dados referentes a partir de 2012 com o enfoque na qualidade da informação como "produto", têm-se (Quadro 3): Silva e Carreiro (2013); Raupp e Pinho (2014); Moraes Junior, Carneiro e Silva Neto (2015); Raupp e Pinho (2015); Albuquerque e Hermida (2016); Amorim e Almada (2016); Jahns e Raupp (2016); Andrade e Raupp (2017); e Andrade, Raupp e Pinho (2017).

\section{Quadro 3 - Considerações recorrentes entre os estudos com base na LAI que utilizaram um método de avaliação da qualidade da informação pública com enfoque na informação como "produto"}

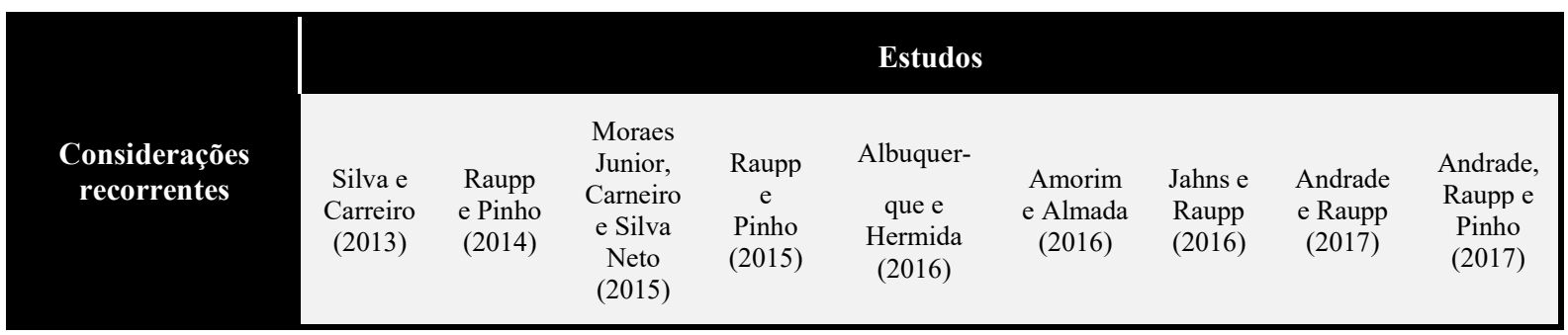




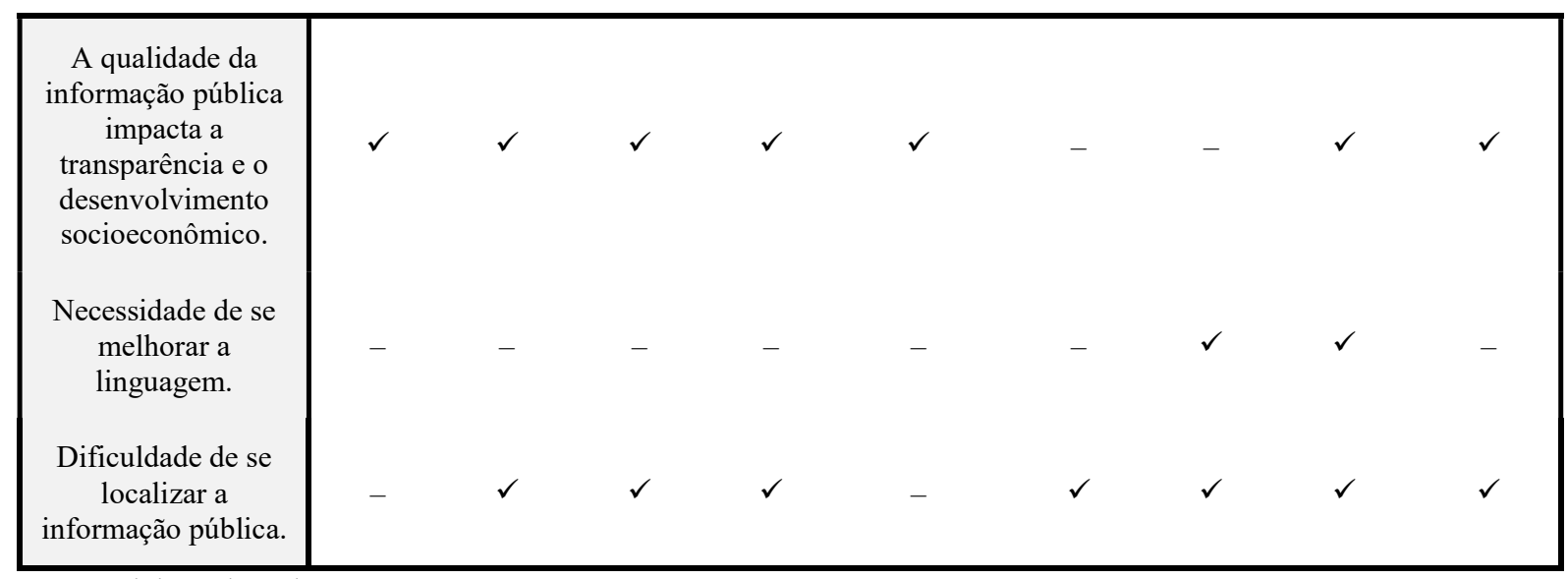

Fonte: elaborado pelos autores.

É mister observar que as considerações observadas a partir desses artigos reafirmam as justificativas para elaboração desta pesquisa, sendo algumas delas recorrentes entre esses estudos.

\section{METODOLOGIA DE PESQUISA}

Quanto à natureza, a presente pesquisa é "aplicada" por tratar de conhecimento científico voltado à solução de um problema (PRODANOV; FREITAS, 2013), qual seja um meio de se mensurar a qualidade da informação disponível nos sítios eletrônicos de universidades federais do Brasil.

A forma de abordagem desse problema é "qualitativa-quantitativa" (PRODANOV; FREITAS, 2013): qualitativa, na medida em que buscar-se-á avaliar a qualidade da informação pública disponibilizada por esses sítios; e quantitativa, na medida em que buscarse-á mensurar essa qualidade por meio do IBTIPE.

Quanto ao objetivo, a pesquisa se caracteriza como "descritivo-exploratória" (PRODANOV; FREITAS, 2013), por se propor a analisar toda a informação pública disponível nesses sítios mediante proposição de um método de checklist, embasando-se em "levantamento bibliográfico" (artigos científicos publicados em periódicos) e "levantamento documental" (documentos de organismos internacionais; publicações do governo federal; legislação vigente sobre o tema; e relatórios e afins relativos às universidades federais e à Educação) - realizados de março a dezembro de 2018 - para desenvolvimento e validação do IBTIPE.

No que se refere ao "levantamento bibliográfico", foram utilizadas as bases de dados Google Acadêmico, Portal de Periódicos da CAPES (Coordenação de Aperfeiçoamento de 
Pessoal de Nível Superior), SPELL (Scientific Periodicals Electronic Library) e SCIELO (Scientific Electronic Library Online) para pesquisar as palavras-chave de forma individual e agrupada (de duas em duas e de três em três): "Lei de Acesso à Informação" (principal), "universidades federais", "qualidade da informação", "controle social”, "participação social”, "transparência" e "Administração Pública".

O período de busca relacionado à escolha dos artigos subdivide-se em dois: de $1996 \mathrm{a}$ 2009, contemplando sete estudos complementares à temática desta pesquisa; e de 2011 a 2018, contemplando vinte estudos (principais), publicados após a instituição da LAI e diretamente relacionados à temática desta pesquisa (nove destes associam a transparência pública à qualidade da informação pública para propor algum método de qualidade da informação pública com enfoque na informação como produto).

A exceção de escolha de artigo fora dos períodos supramencionados foi Likert (1932), autor-referência na literatura de técnica de escala, que será adaptada para o método de desenvolvimento do IBTIPE. Ademais, esclarece-se ainda que foi selecionado um livro de Prodanov e Freitas (2013) como base teórica para a elaboração desta metodologia de pesquisa.

No que se refere ao "levantamento documental", dentre os relatórios e afins, os "Relatórios de Pedidos de Acesso à Informação e Solicitantes" (BRASIL, 2018a) vinculados às universidades federais (obtidos via SIC) fazem referência ao período de maio de 2012 (início efetivo da LAI) até dezembro de 2018. Os demais documentos datam de 2018, exceto “Sinopses Estatísticas da Educação Superior", de 2016 (BRASIL, 2016), e "Índice Geral de Cursos" (IGC), de 2017 (BRASIL, 2017b), ambos, porém, em sua última atualização.

Como procedimento técnico para a coleta de dados, será utilizado o "estudo de caso" (PRODANOV; FREITAS, 2013) por meio da informação pública disponível nos sítios eletrônicos de universidades federais (coletada e analisada em janeiro e fevereiro de 2019) conforme quesitos do IBTIPE (a partir do que dispõe a LAI) - especificamente de uma amostragem das vinte melhores universidades federais (UFABC, UFBA, UFC, UFG, UFJF, UFLA, UFMG, UFPE, UFPR, UFRGS, UFRJ, UFRN, UFRPE, UFSC, UFSCAR, UFSM, UFU, UFV, UNB e UNIFESP) em 2017, segundo o IGC, indicador do Instituto Nacional de Estudos e Pesquisas Educacionais Anísio Teixeira (INEP) que avalia a qualidade das instituições de Educação Superior do País.

\section{APRESENTAÇÃO DO IBTIPE}


O IBTIPE se apresenta como um índice bidimensional de transparência verificável a partir da qualidade da informação disponível, nos sítios eletrônicos de universidades federais do Brasil. Essa verificação é realizada em forma de checklist e procura "maximizar" a concepção teórica de "qualidade da informação" ora exposta (na seção 1.4), sendo a descrição de cada quesito composta pelo conteúdo informacional em alinhamento a aspectos de: atributos teóricos de informação (atualização, autenticidade, integridade e primariedade); tecnologia; estrutura; e acessibilidade (disponibilização de documentos em formatos acessíveis, uso de linguagem verbal de fácil compreensão e padronização de elementos de acessibilidade digital).

Entendendo-se a participação e o controle sociais como práticas de cidadania, o instrumento em questão destina-se a toda a sociedade e AP brasileiras. De forma mais específica, o interesse maior no instrumento possivelmente será dos discentes dessas universidades e de órgãos diretos como o Ministério da Educação (MEC), de controle como o CGU e o Tribunal de Contas da União (TCU) e de apoio como a CAPES.

A avaliação da qualidade proposta pelo IBTIPE tem foco na informação como produto, com atributos determinados por uma abordagem: intuitiva por se basear nas orientações do Guia de Transparência Ativa para Órgãos e Entidades do Poder Executivo Federal (BRASIL, 2017a) e do e-MAG (BRASIL, 2014); e teórica por se basear nos estudos de Amorim e Almada (2016) e Silva e Carreiro (2013). Em menor proporção, há ainda uma abordagem empírica na determinação dos atributos de qualidade das informações complementares do tipo "menos importante", por estes se basearem em demandas do usuário.

Em consonância à LAI, o dimensionamento a que se refere o índice parte da caracterização de cada modalidade de transparência identificada nesses sítios. Desse modo, da dimensão denominada "Sobredimensão Transparência Global" (STG) por este trabalho, fazem parte três subdimensões, assim denominadas e descritas:

1) "Subdimensão Transparência Ativa" (STA) - composta pela informação básica, entendida como "importante e essencial pela LAI" (devendo constar na seção "Acesso à Informação" própria do sítio), com quesitos baseados nas orientações gerais do Guia de Transparência Ativa para Órgãos e Entidades do Poder Executivo Federal (BRASIL, 2017a) e nas orientações do e-MAG (BRASIL, 2014);

2) "Subdimensão Transparência Proativa Primária" (STPP) - composta pela informação complementar primária, entendida como a informação do tipo "importante, mas não essencial pela LAI" (complementares que se encontram na seção "Acesso à Informação"), com quesitos levantados a partir dos sítios da amostra; 
3) "Subdimensão Transparência Proativa Secundária" (STPS) - composta pela informação complementar secundária, entendida como a informação do tipo "menos importante" (complementares mais requeridas via SIC e que não se encontram, de fato, na seção "Acesso à Informação", nos sítios), com quesitos levantados a partir dos temas/assuntos mais requeridos ao SIC, desde a efetivação da LAI (maio de 2012) até dezembro de 2018, por meio dos "Relatórios de Pedidos de Acesso à Informação e Solicitantes" (BRASIL, 2018a);

Nesse contexto, o IBTIPE considera, na prática, as duas seguintes dimensões como as mais importantes: a STA como reflexo do cumprimento factual da lei e a STG como reflexo de transparência em sentido amplo. Esclarece-se que, esta última dimensão, ao ter como componente a STPS (que contempla informações que nem sempre estão, de fato, disponíveis nos sítios), sugere o exercício de uma transparência tida como a "ideal".

Desse modo, ficam estabelecidos os seguintes pesos informacionais, tendo-se como referência a STG (Quadro 4): 1) informação importante e essencial pela LAI - peso 7 (70\%); 2) informação importante, mas não essencial pela LAI - peso 2 (20\%); e, 3) informação menos importante - peso $1(10 \%)$.

\section{Quadro 4 - Pesos do Índice Bidimensional de Transparência da Informação Público- Eletrônica (IBTIPE)}

\begin{tabular}{|c|c|c|c|c|c|}
\hline \multicolumn{2}{|c|}{ Dimensão } & Obrigatoriedade & Informação & Característica da informação & Peso \\
\cline { 4 - 6 } & $\underline{\text { STA }}$ & Factual & Básica & $\begin{array}{c}\text { Importante e essencial pela LAI (deve constar na } \\
\text { seção "Acesso à Informação") }\end{array}$ & 7 \\
\cline { 4 - 7 } & STPP & Não factual & Complementar & $\begin{array}{c}\text { Importante, mas não essencial pela LAI (encontra- } \\
\text { se nos sítios, na seção “Acesso à Informação") }\end{array}$ & 2 \\
\cline { 5 - 7 } & STPS & $\begin{array}{c}\text { Menos importante (mais requerida via SIC e que } \\
\text { não se encontra, de fato, na seção "Acesso à } \\
\text { Informação", nos sítios) }\end{array}$ & 1 \\
\hline
\end{tabular}

Fonte: elaborado pelos autores com base em Silva e Carreiro (2013).

O valor máximo de quesito (VMQ) terá variação de acordo com cada subdimensão de transparência, sendo determinado pelo "peso da subdimensão" sobre o "total de quesitos da subdimensão". Definido o VMQ, estabelece-se o critério de avaliação da qualidade da informação, composto por cinco opções de atributo por quesito, consoante Tabela 1. Esclarece-se que, neste trabalho, uma informação completa é entendida pelo atendimento a itens técnicos como: localização na seção “Acesso à Informação" e em link específico; 
atualização; autenticidade; integridade; primariedade; possibilidade de download em formato $O D F$; entre outros. Já uma informação compreensível refere-se à apresentação de itens do conteúdo desta em conjunto ao atendimento do item referente à utilização de uma linguagem verbal de fácil compreensão.

Tabela 1 - Critério do Índice Bidimensional de Transparência da Informação Público-

Eletrônica (IBTIPE) referente à avaliação da qualidade da informação

\begin{tabular}{c|c} 
Atributo & Valor \\
\hline Informação completa e compreensível (ICC) & VMQ \\
Informação completa, mas incompreensível (ICI) & VMQ x 0,75 \\
Informação incompleta, mas compreensível (IIC) & VMQ x 0,50 \\
Informação incompleta e incompreensível (III) & VMQ x 0,25 \\
Informação inexistente (IIN) & 0 \\
\hline
\end{tabular}

Fonte: elaborada pelos autores com base em Silva e Carreiro (2013).

Os atributos são caracterizados de forma semelhante ao método de Amorim e Almada (2016), exposto pelo Quadro 5, mediante as seguintes adaptações: as denominações "muito bom", "bom", "regular", "fraco" e "não existe" corresponderão, respectivamente, a ICC, ICI, IIC, III e IIN; e a pontuação será definida conforme Tabela 1.

\section{Quadro 5 - Exemplo do método de Amorim e Almada (2016)}

\begin{tabular}{|l|l|c|}
\hline Aspecto* avaliado & \multicolumn{1}{c|}{ Critérios** de análise } & Pontuação \\
\hline & $\begin{array}{l}\text { Muito bom - (1) quando há informações atualizadas sistematicamente sobre } \\
\text { licitações do governo, já realizadas e em andamento há pelo menos três anos; (2) } \\
\text { quando há documentos, formato em que são publicados com explicações detalhadas } \\
\text { e didáticas (textos, gráficos, tabelas, infográficos, áudio e vídeo); (3) quando há } \\
\text { data da postagem, período de cobertura, fonte e indicação do responsável pela } \\
\text { prestação das informações; e (4) quando há meios de contato. }\end{array}$ & $\mathbf{4}$ \\
\cline { 2 - 4 } Licitações & \begin{tabular}{l} 
Bom - quando o sítio eletrônico não atende apenas ao item 2. \\
\cline { 2 - 4 }
\end{tabular} & $\mathbf{3}$ \\
\cline { 2 - 4 } & $\begin{array}{l}\text { Fraco - quando o sítio eletrônico apresenta pelo menos um dos itens descritos } \\
\text { acima. }\end{array}$ & $\mathbf{2}$ \\
\hline & $\begin{array}{l}\text { Não existe - quando não há informações atualizadas sistematicamente sobre } \\
\text { licitações do governo, no sítio eletrônico. }\end{array}$ & $\mathbf{0}$ \\
\hline
\end{tabular}


*Quesito. **Atributos.

Fonte: Amorim e Almada (2016).

A partir de todo o embasamento teórico exposto e realizando-se uma adaptação descritiva a partir das versões dos modelos de Amorim e Almada (2016) e Silva e Carreiro (2013), apresenta-se, mediante Quadro 6, o modelo-padrão de checklist do IBTIPE aplicável a qualquer quesito das dimensões de transparência STA, STPP e STPS.

\section{Quadro 6 - Modelo-padrão de checklist do IBTIPE}

\begin{tabular}{|l|c|}
\multicolumn{1}{|c|}{ Descrição do atributo } & Valor \\
\hline $\begin{array}{l}\text { ICC - O principal sítio eletrônico da universidade federal apresenta o quesito: (1) na seção “Acesso à } \\
\text { Informação", em link específico; (2) com data de atualização (do último mês); (3) com autenticidade } \\
\text { (identificação do servidor, equipamento ou sistema que processou a informação); (4) com integridade } \\
\text { (informaçáo é identificada pela fonte e acessada via link de redirecionamento a sua página de origem) ou } \\
\text { primariedade (informação apresentada com identificação da fonte); (5) com possibilidade de download em } \\
\text { formato ODF; (6) com conteúdo informacional completo; e (7) em linguagem verbal de fácil } \\
\text { compreensão (um tópico por parágrafo; sentenças na voz ativa e organizadas preferencialmente na ordem } \\
\text { sujeito-verbo-objeto; períodos curtos; termos comuns ao público em geral; explicação para siglas, } \\
\text { abreviaturas e outros termos menos comuns; técnicas que facilitem a identificação visual de tópicos; e } \\
\text { referências claras a pronomes e outras partes do texto ou a links). }\end{array}$ & VMQ \\
\hline $\begin{array}{l}\text { ICI - O principal sítio eletrônico da universidade federal cumpre totalmente os itens } 1 \text { a } 5 \text { deste quesito, } \\
\text { porém cumpre, no máximo, um dos itens } 6 \text { e 7. }\end{array}$ & VMQx0,75 \\
\hline $\begin{array}{l}\text { IIC - O principal sítio eletrônico da universidade federal cumpre totalmente até quatro dos itens 1 a 5 e os } \\
\text { itens } 6 \text { e } 7 \text { deste quesito. }\end{array}$ & VMQx0,50 \\
\hline $\begin{array}{l}\text { III - O principal sítio eletrônico da universidade federal cumpre até quatro dos itens } 1 \text { a } 5 \text { deste quesito e, } \\
\text { no máximo, um dos itens } 6 \text { e 7. }\end{array}$ & VMQx0,25 \\
\hline IIN - O principal sítio eletrônico da universidade federal não cumpre nem um item deste quesito. & 0 \\
\hline
\end{tabular}

Fonte: elaborado pelos autores.

A checklist para a STA contempla os seguintes trinta e seis (36) quesitos de informação básica (por eixo temático): 1) "Ferramentas e Aspectos Tecnológicos" (banner (link) intitulado "Acesso à Informação"; barra de identidade do governo federal; e ferramenta para pesquisa de conteúdo; 2) "Institucional” (estrutura organizacional; competências; base jurídica da estrutura organizacional e das competências; principais cargos e seus ocupantes; contatos; agenda de autoridades; e horários de atendimento das unidades); 3) "Ações e Programas" (lista de programas, projetos, ações, obras e atividades; programas que resultem em renúncias de receitas; programas financiados pelo Fundo de Amparo do Trabalhador (FAT); e carta de serviços ao cidadão); 4) "Participação Social" (Ouvidoria; audiências e consultas públicas previstas e realizadas; conselhos e órgãos colegiados; conferências 
previstas e realizadas; e outras ações); 5) "Auditorias" (relatórios de gestão; relatórios e certificados de auditoria; processos de contas anuais; e Relatório Anual de Atividades da Auditoria Interna); 6) "Convênios e Transferências" (transferências de recursos da União realizadas mediante convênios, contratos de repasse e termos de cooperação, ou instrumentos congêneres com órgãos ou entidades públicas ou privadas sem fins lucrativos; e transferências constitucionais e legais e as de renda direta ao cidadão); 7) "Receitas e Despesas" (receitas; e execução orçamentária e financeira detalhada contendo quadro de detalhamento de programas, quadro de execução de despesas e despesas com diárias e passagens); 8) "Licitações e Contratos" (licitações realizadas e em andamento; e contratos firmados e notas de empenho expedidas); 9) "Servidores Públicos" (concursos públicos de provimentos de cargos; relação dos servidores públicos - efetivos ou não - lotados ou em exercício; e relação completa de terceirizados); 10) "Informações Classificadas" (rol de informações classificadas; e rol de informações desclassificadas nos últimos 12 meses); 11) "SIC" (informações gerais sobre o SIC); 12) "Perguntas Frequentes" (perguntas/respostas mais frequentes); e 13) "Dados Abertos" (Plano de Dados Abertos).

Já a checklist para a STPP contempla dezesseis (16) quesitos de informações complementares relacionados aos seguintes eixos temáticos: Institucional (apresentação; calendário; comitês e comissões permanentes; e fundações de apoio credenciadas); Ações e Programas (boletim de atos normativos; consulta de processos; guias e manuais; mapeamento de processos; repositório de produção científica; e títulos e condecorações); Participação Social (relatórios da Ouvidoria); Auditorias (Auditoria Interna; indicadores; e Plano Anual de Auditoria Interna); e SIC (apresentação da LAI; e links úteis).

Por fim, a checklist para a STPS é composta por dez (10) quesitos de informações complementares vinculados aos seguintes eixos temáticos: Institucional (bases legais da Educação); Ações e Programas (ações culturais; assistência estudantil; cursos de capacitação, palestras e seminários abertos à sociedade em geral; cursos de graduação; cursos de pósgraduação; política de saúde; e política de sustentabilidade); e Servidores Públicos (legislação; e plano de carreira).

Assim que for realizada a checagem de cada quesito, será atribuído o valor final da qualidade da informação de cada dimensão de transparência, o que corresponderá, no caso da STA, ao nível de cumprimento factual da LAI pelos sítios eletrônicos da amostra (conforme Tabela 2), e, nos casos da STPP, STPS e STG, ao nível de transparência (complementar ou total) de cada um desses sítios, Tabela 3. 


\section{Tabela 2 - IBTIPE - Nível de cumprimento factual da LAI}

\section{Valor da STA}

$\mathrm{STA}=7$

$5,6<\mathrm{STA}<7$

$4,2<\mathrm{STA} \leq 5,6$

$2,8<\mathrm{STA} \leq 4,2$

$1,4<\mathrm{STA} \leq 2,8$

$0<\mathrm{STA} \leq 1,4$

$\mathrm{STA}=0$

\section{Nível de cumprimento factual da LAI}

Cumprimento total

Cumprimento avançado

Cumprimento significativo

Cumprimento moderado

Cumprimento frágil

Cumprimento mínimo

Cumprimento inexistente

Fonte: elaborada pelos autores com base em Amorim e Almada (2016) e Likert (1932).

Tabela 3 - IBTIPE - Nível de transparência

\begin{tabular}{c|c|c|c|}
\hline Valor da STPP & Valor da STPS & Valor da STG & Nível de transparência \\
\hline $\mathrm{STPP}=2$ & $\mathrm{STPS}=1$ & $\mathrm{STG}=10$ & Transparência total \\
$1,6<\mathrm{STPP}<2$ & $0,8<\mathrm{STPS}<1$ & $8<\mathrm{STG}<10$ & Transparência avançada \\
$1,2<\mathrm{STPP} \leq 1,6$ & $0,6<\mathrm{STPS} \leq 0,8$ & $6<\mathrm{STG} \leq 8$ & Transparência significativa \\
$0,8<\mathrm{STPP} \leq 1,2$ & $0,4<\mathrm{STPS} \leq 0,6$ & $4<\mathrm{STG} \leq 6$ & Transparência moderada \\
$0,4<\mathrm{STPP} \leq 0,8$ & $0,2<\mathrm{STPS} \leq 0,4$ & $2<\mathrm{STG} \leq 4$ & Transparência frágil \\
$0<\mathrm{STPP} \leq 0,4$ & $0<\mathrm{STPS} \leq 0,2$ & $0<\mathrm{STG} \leq 2$ & Transparência mínima \\
$\mathrm{STPP}=0$ & $\mathrm{STPS}=0$ & $\mathrm{STG}=0$ & Transparência inexistente \\
\hline
\end{tabular}

Fonte: elaborada pelos autores com base em Amorim e Almada (2016) e Likert (1932).

Contabilizados os valores de cada dimensão de transparência, serão elaborados os seguintes rankings relativos aos sítios da amostra: qualidade da informação (básica e complementar) por quesito; nível de cumprimento factual da LAI; e nível de transparência das informações complementar e total. Caso haja valor de dimensão igual entre dois ou mais sítios, o critério de desempate será o maior número de ocorrências de seus atributos de informação, obedecendo-se a ordem decrescente de valor de atributo (ICC > ICI $>$ IIC $>$ III $>$ IIN).

\section{RESULTADOS: VALIDAÇÃO DO IBTIPE}


A coleta de dados oriundos dos sítios eletrônicos das universidades federais brasileiras da amostra ocorreu de 18 a 29 de janeiro de 2019, com duração total aproximada de 31 horas (média de 1 hora e 33 minutos por sítio). A seguir, apresenta-se a Tabela 4, com os resultados do IBTIPE relativos ao conjunto desses sítios, contendo: o número de ocorrências de atributo de informação de cada dimensão, o valor médio de cada dimensão (seguido de sua porcentagem relativa) e a denominação correlativa ao nível de cumprimento factual da LAI (no caso da STA) ou ao nível de transparência complementar ou total (nos casos da STPP, STPS e STG).

Tabela 4 - Resultados do IBTIPE relativos ao conjunto dos sítios da amostra

\begin{tabular}{|c|c|c|c|c|c|c|c|c|}
\hline \multirow[b]{2}{*}{ Dimensão } & \multicolumn{5}{|c|}{ Número de ocorrências de atributo de informação } & \multirow{2}{*}{$\begin{array}{c}\text { Média } \\
\text { aritmética do } \\
\text { valor da } \\
\text { dimensão } \\
(\%)\end{array}$} & \multirow[b]{2}{*}{$\begin{array}{c}\text { Nível de } \\
\text { cumprimento } \\
\text { factual da LAI }\end{array}$} & \multirow[b]{2}{*}{$\begin{array}{c}\text { Nível de } \\
\text { transparência }\end{array}$} \\
\hline & $\begin{array}{l}\text { ICC } \\
(\%)\end{array}$ & ICI (\%) & IIC (\%) & III (\%) & IIN (\%) & & & \\
\hline STA & - & $\begin{array}{c}9 \\
(1,25 \%)\end{array}$ & $\begin{array}{c}241 \\
(33,47 \%)\end{array}$ & $\begin{array}{c}208 \\
(28,88 \%)\end{array}$ & $\begin{array}{c}262 \\
(36,38 \%)\end{array}$ & $\begin{array}{c}1,747 \\
(24,96 \%)\end{array}$ & $\begin{array}{l}\text { Cumprimento } \\
\text { frágil }\end{array}$ & - \\
\hline STPP & $\begin{array}{c}1 \\
(0,31 \%)\end{array}$ & $\begin{array}{c}2 \\
(0,62 \%)\end{array}$ & $\begin{array}{c}119 \\
(37,18 \%)\end{array}$ & $\begin{array}{c}34 \\
(10,62 \%)\end{array}$ & $\begin{array}{c}164 \\
(51,25 \%)\end{array}$ & $\begin{array}{l}0,440 \\
(22 \%)\end{array}$ & - & $\begin{array}{c}\text { Transparência } \\
\text { frágil }\end{array}$ \\
\hline STPS & - & $\begin{array}{c}1 \\
(0,5 \%)\end{array}$ & $\begin{array}{c}117 \\
(58,50 \%)\end{array}$ & $\begin{array}{c}11 \\
(5,5 \%)\end{array}$ & $\begin{array}{c}71 \\
(35,50 \%)\end{array}$ & $\begin{array}{l}0,310 \\
(31 \%)\end{array}$ & - & $\begin{array}{l}\text { Transparência } \\
\text { frágil }\end{array}$ \\
\hline STG & $\begin{array}{c}1 \\
(0,08 \%)\end{array}$ & $\begin{array}{c}12 \\
(0,96 \%)\end{array}$ & $\begin{array}{c}476 \\
(38,38 \%)\end{array}$ & $\begin{array}{c}253 \\
(20,40 \%)\end{array}$ & $\begin{array}{c}498 \\
(40,16 \%)\end{array}$ & $\begin{array}{c}2,497 \\
(24,97 \%)\end{array}$ & - & $\begin{array}{l}\text { Transparência } \\
\text { frágil }\end{array}$ \\
\hline
\end{tabular}

Fonte: elaborada pelos autores.

Com relação à STA do conjunto dos sítios, foram encontradas as seguintes ocorrências de atributo de informação segundo a Tabela 4: 9 ICI (1,25\% do total de quesitos da STA do conjunto dos sítios), 241 IIC (33,47\% do total de quesitos da STA do conjunto dos sítios), 208 III (28,88\% do total de quesitos da STA do conjunto dos sítios) e 262 IIN (36,38\% do total de quesitos da STA do conjunto dos sítios). Logo, embora tenham sido encontrados 458 quesitos com valor de fato $(63,61 \%$ do total de quesitos da STA do conjunto dos sítios), o valor médio da STA totalizou 1,747 (24,96\% do total possível da STA) na prática, o que representa um nível de "cumprimento (factual) frágil” da LAI conforme o IBTIPE.

Ressalta-se que, em vista da obrigatoriedade imposta pela LAI, foi preocupante a observação, em catorze (14) sítios da amostra, da ausência total de quesitos de sete (7) eixos temáticos da STA, apresentados em ordem decrescente de ausências: "Participação Social" (ausente em onze (11) sítios); "Dados Abertos" (ausente em seis (6) sítios); "Informações Classificadas" (ausente em quatro (4) sítios); "Ações e Programas" (ausente em três (3) 
sítios); e "Perguntas Frequentes", "Receitas e Despesas" e "SIC" (ausentes em um (1) sítio cada).

No contexto de desempenho agrupado da verificação dos sítios, justifica-se a obtenção de baixas médias de valores dimensionais em virtude, essencialmente, das baixíssimas incidências dos atributos de maior valor (ICC e ICI) e a alta incidência do atributo IIN, apoiado pela considerável incidência do atributo de menor valor (III). É importante esclarecer que, de 1.240 checagens de quesitos nos vinte (20) sítios da amostra, houve somente uma ocorrência do atributo ICC, ou seja, somente um (1) quesito (de cunho complementar - da STPP) obteve valor máximo.

Em seguida, são apresentados os rankings de transparência (Tabelas 5, 6, 7 e 8), elaborados a partir dos resultados de cada dimensão de transparência obtidos por cada sítio da amostra.

Tabela 5 - Ranking de cumprimento factual da LAI

\begin{tabular}{|c|c|c|c|c|c|c|c|c|}
\hline \multirow{2}{*}{ Posição } & \multirow{2}{*}{ Universidade } & \multicolumn{5}{|c|}{$\begin{array}{l}\text { Número de ocorrências de atributo de } \\
\text { informação }\end{array}$} & \multirow{2}{*}{$\begin{array}{l}\text { Valor da } \\
\text { STA }(\%)\end{array}$} & \multirow{2}{*}{$\begin{array}{l}\text { Nível de cumprimento } \\
\text { (factual) da LAI }\end{array}$} \\
\hline & & ICC & ICI & IIC & III & IIN & & \\
\hline $1^{\mathrm{a}}$ & UFABC & - & 1 & 17 & 15 & 3 & $\mathbf{2 , 5 3 5}(36,21 \%)$ & Cumprimento frágil \\
\hline $2^{\mathrm{a}}$ & UFRJ & - & - & 17 & 15 & 4 & $\mathbf{2 , 3 4 0}(33,42 \%)$ & Cumprimento frágil \\
\hline $3^{\mathrm{a}}$ & UFLA & - & - & 16 & 15 & 5 & $\mathbf{2 , 2 9 1}(32,72 \%)$ & Cumprimento frágil \\
\hline $4^{a}$ & UFC & - & - & 14 & 16 & 6 & $\mathbf{2 , 1 4 5}(30,64 \%)$ & Cumprimento frágil \\
\hline $5^{\mathrm{a}}$ & UFSM & - & 1 & 16 & 7 & 12 & $\mathbf{2 , 0 4 7}(29,24 \%)$ & Cumprimento frágil \\
\hline $6^{\mathrm{a}}$ & UFSCAR & - & 1 & 16 & 6 & 13 & $\mathbf{1 , 9 9 8}(28,54 \%)$ & Cumprimento frágil \\
\hline $7^{\mathrm{a}}$ & UFU & - & 3 & 11 & 9 & 13 & $1,950(27,85 \%)$ & Cumprimento frágil \\
\hline $8^{\mathrm{a}}$ & UFG & - & - & 16 & 7 & 13 & $\mathbf{1 , 9 0 1}(27,15 \%)$ & Cumprimento frágil \\
\hline $9^{\mathrm{a}}$ & UFPE & - & - & 16 & 6 & 14 & $\mathbf{1 , 8 5 2}(26,45 \%)$ & Cumprimento frágil \\
\hline $10^{\mathrm{a}}$ & UFBA & - & 1 & 12 & 8 & 15 & $\mathbf{1 , 7 0 6}(24,37 \%)$ & Cumprimento frágil \\
\hline $11^{\mathrm{a}}$ & UFSC & - & - & 12 & 11 & 13 & $\mathbf{1 , 7 0 6}(24,37 \%)$ & Cumprimento frágil \\
\hline $12^{\mathrm{a}}$ & UFPR & - & - & 13 & 8 & 15 & $\mathbf{1 , 6 5 7}(23,67 \%)$ & Cumprimento frágil \\
\hline $13^{\mathrm{a}}$ & UFV & - & - & 12 & 10 & 14 & $\mathbf{1 , 6 5 7}(23,67 \%)$ & Cumprimento frágil \\
\hline $14^{\mathrm{a}}$ & UNB & - & 1 & 6 & 17 & 12 & $\mathbf{1 , 5 6 0}(22,28 \%)$ & Cumprimento frágil \\
\hline $15^{\mathrm{a}}$ & UNIFESP & - & - & 8 & 14 & 14 & $\mathbf{1 , 4 6 2}(20,88 \%)$ & Cumprimento frágil \\
\hline
\end{tabular}




\begin{tabular}{llllllll|l|l|l}
$16^{\mathrm{a}}$ & UFJF & - & 1 & 10 & 6 & 19 & $\mathbf{1 , 4 1 3}(20,18 \%)$ & Cumprimento frágil \\
\hline $17^{\mathrm{a}}$ & UFRN & - & - & 11 & 5 & 20 & $\mathbf{1 , 2 6 7}(18,10 \%)$ & Cumprimento mínimo \\
\hline $18^{\mathrm{a}}$ & UFRPE & - & - & 8 & 9 & 19 & $\mathbf{1 , 2 1 8}(17,40 \%)$ & Cumprimento mínimo \\
\hline $19^{\mathrm{a}}$ & UFMG & - & - & 7 & 9 & 20 & $\mathbf{1 , 1 2 1}(16,01 \%)$ & Cumprimento mínimo \\
\hline $20^{\mathbf{a}}$ & UFRGS & - & - & 3 & 15 & 18 & $\mathbf{1 , 0 2 3}(14,61 \%)$ & Cumprimento mínimo \\
\hline
\end{tabular}

Fonte: elaborada pelos autores.

Diante da Tabela 5, observa-se, um baixo cumprimento factual da LAI pelos sítios eletrônicos da amostra, sendo que dezesseis (16) deles (UFABC, UFRJ, UFLA, UFC, UFSM, UFSCAR, UFU, UFG, UFPE, UFBA, UFSC, UFPR, UFV, UNB, UNIFESP e UFJF) se situaram no nível de "cumprimento (factual) frágil", e os quatro (4) restantes (UFRN, UFRPE, UFMG e UFRGS), no nível de "cumprimento (factual) mínimo".

Logo, o sítio que apresentou o maior nível de cumprimento factual da LAI foi o da UFABC ("frágil"), com o valor 2,535 (36,21\% do valor total da STA). Por outro lado, o sítio que apresentou o menor nível de cumprimento factual da LAI foi o da UFRGS ("mínimo"), com o valor $1,023(14,61 \%$ do valor total da STA), destacando-se negativamente pelo alto número de ocorrências do atributo IIN (18 vezes).

Dessa forma, os seguintes sítios eletrônicos podem ser considerados benchmarks para os demais da amostra, visando à busca por uma informação completa e compreensível, no que se refere ao cumprimento factual da LAI:

1) UFABC e UFRJ $\left(1^{\mathrm{a}}\right.$ e $2^{\mathrm{a}}$ posições do ranking de cumprimento factual da LAI respectivamente), pois, além da obtenção dos menores números de ocorrências do atributo IIN (3 e 4 vezes respectivamente), ainda obtiveram o maior número de ocorrências do atributo IIC (17 vezes cada). Assim, dos quesitos verificados que obtiveram algum valor de fato, a maioria destes apresentou informação mais compreensível do que completa, ou seja, com maior cumprimento de itens relativos ao conteúdo informacional aliados ao uso de linguagem verbal de fácil compreensão;

2) UFU (ainda que tenha ficado na $7^{\mathrm{a}}$ posição do ranking de cumprimento factual da LAI), pois obteve o maior número de ocorrências do atributo ICI (3 vezes), ou seja, o sítio mais próximo, por três vezes, de obter o VMQ (o atributo ICC). Assim, apresentou informação mais completa do que compreensível (somando-se as 3 ocorrências de ICI às 9 de III), ou seja, com maior cumprimento de itens técnicos de informação como atualização, autenticidade, integridade, primariedade, tecnologia, estrutura e disponibilização de documentos em formatos acessíveis. 
Tabela 6 - Ranking de transparência da informação complementar primária

\begin{tabular}{|c|c|c|c|c|c|c|c|c|}
\hline \multirow{2}{*}{ Posição } & \multirow{2}{*}{ Universidade } & \multicolumn{5}{|c|}{$\begin{array}{l}\text { Número de ocorrências de atributo de } \\
\text { informação da STPP }\end{array}$} & \multirow{2}{*}{$\begin{array}{l}\text { Valor da } \\
\text { STPP }\end{array}$} & \multirow{2}{*}{ Nível de transparência } \\
\hline & & ICC & ICI & IIC & III & IIN & & \\
\hline $1^{\mathrm{a}}$ & UFPE & - & - & 11 & 2 & 3 & $\mathbf{0 , 7 5 0}(37,50 \%)$ & Transparência frágil \\
\hline $2^{\mathrm{a}}$ & UFU & 1 & 2 & 6 & 1 & 6 & $\mathbf{0 , 7 1 8}(35,90 \%)$ & Transparência frágil \\
\hline $3^{\mathrm{a}}$ & UFSM & - & - & 9 & - & 7 & $\mathbf{0 , 5 6 2}(28,10 \%)$ & Transparência frágil \\
\hline $4^{\mathrm{a}}$ & UFRJ & - & - & 8 & 2 & 6 & $\mathbf{0 , 5 6 2}(28,10 \%)$ & Transparência frágil \\
\hline $5^{\mathrm{a}}$ & UFLA & - & - & 8 & 1 & 7 & $\mathbf{0 , 5 3 1}(26,55 \%)$ & Transparência frágil \\
\hline $5^{\mathrm{a}}$ & UFRN & - & - & 8 & 1 & 7 & $\mathbf{0 , 5 3 1}(26,55 \%)$ & Transparência frágil \\
\hline $6^{\mathrm{a}}$ & UFSC & - & - & 8 & - & 8 & $\mathbf{0 , 5 0 0}(25 \%)$ & Transparência frágil \\
\hline $7^{\mathrm{a}}$ & UFABC & - & - & 7 & 2 & 7 & $\mathbf{0 , 5 0 0}(25 \%)$ & Transparência frágil \\
\hline $8^{\mathrm{a}}$ & UNIFESP & - & - & 6 & 3 & 7 & $\mathbf{0 , 4 6 8}(23,40 \%)$ & Transparência frágil \\
\hline $9^{\mathrm{a}}$ & UFRPE & - & - & 6 & 2 & 8 & $\mathbf{0 , 4 3 7}(21,85 \%)$ & Transparência frágil \\
\hline $9^{\mathrm{a}}$ & UFSCAR & - & - & 6 & 2 & 8 & $\mathbf{0 , 4 3 7}(21,85 \%)$ & Transparência frágil \\
\hline $10^{\mathrm{a}}$ & UFPR & - & - & 6 & 1 & 9 & $\mathbf{0 , 4 0 6}(20,30 \%)$ & Transparência frágil \\
\hline $11^{\mathrm{a}}$ & UFJF & - & - & 5 & 3 & 8 & $\mathbf{0 , 4 0 6}(20,30 \%)$ & Transparência frágil \\
\hline $11^{\mathrm{a}}$ & UNB & - & - & 5 & 3 & 8 & $\mathbf{0 , 4 0 6}(20,30 \%)$ & Transparência frágil \\
\hline $12^{\mathrm{a}}$ & UFG & - & - & 4 & 2 & 10 & $\mathbf{0 , 3 1 2}(15,60 \%)$ & Transparência mínima \\
\hline $13^{\mathrm{a}}$ & UFV & - & - & 4 & 1 & 11 & $\mathbf{0 , 2 8 1}(14,05 \%)$ & Transparência mínima \\
\hline $14^{\mathrm{a}}$ & UFRGS & - & - & 3 & 3 & 10 & $\mathbf{0 , 2 8 1}(14,05 \%)$ & Transparência mínima \\
\hline $15^{\mathrm{a}}$ & UFBA & - & - & 3 & 2 & 11 & $\mathbf{0 , 2 5 0}(12,50 \%)$ & Transparência mínima \\
\hline $15^{\mathrm{a}}$ & UFC & - & - & 3 & 2 & 11 & $\mathbf{0 , 2 5 0}(12,50 \%)$ & Transparência mínima \\
\hline $16^{\mathrm{a}}$ & UFMG & - & - & 3 & 1 & 12 & $\mathbf{0 , 2 1 8}(10,90 \%)$ & Transparência mínima \\
\hline
\end{tabular}

Fonte: elaborada pelos autores.

Diante da Tabela 6, observa-se uma baixa transparência da informação complementar primária referente aos sítios da amostra, sendo que catorze (14) deles (UFPE, UFU, UFSM, UFRJ, UFLA, UFRN, UFSC, UFABC, UNIFESP, UFRPE, UFSCAR, UFPR, UFJF e UNB) 
se situaram no nível de "transparência frágil", e os seis (6) restantes (UFG, UFV, UFRGS, UFBA, UFC e UFMG), no nível de "transparência mínima".

Logo, o sítio que apresentou o maior nível de transparência da informação complementar primária foi o da UFPE ("transparência frágil"), com o valor 0,750 (37,50\% do valor total da STPP). Por outro lado, o sítio que apresentou o menor nível de transparência da informação complementar primária foi o da UFMG ("transparência mínima"), com o valor 0,218 (10,90\% do valor total da STPP), destacando-se negativamente pelo alto número de ocorrências do atributo IIN (12 vezes).

Dessa forma, os seguintes sítios eletrônicos podem ser considerados benchmarks para os demais da amostra, visando à busca por uma informação completa e compreensível, no que se refere à transparência da informação complementar primária:

1) UFPE ( $1^{\mathrm{a}}$ posição do ranking de transparência da informação complementar primária), pois, além da obtenção do menor número de ocorrências do atributo IIN (3 vezes), ainda obteve o maior número de ocorrências do atributo IIC (11 vezes). Assim, dos quesitos verificados que obtiveram algum valor de fato, a maioria destes apresentou informação mais compreensível do que completa, ou seja, com maior cumprimento de itens relativos ao conteúdo informacional aliados ao uso de linguagem verbal de fácil compreensão;

2) UFU ( $2^{\mathrm{a}}$ posição do ranking de transparência da informação complementar primária), pois foi o único sítio a obter o VMQ (o atributo ICC por 1 vez) e o atributo ICI (2 vezes), ou seja, o sítio que melhor conseguiu apresentar um equilíbrio entre informação completa e compreensível, ou seja, dos quesitos verificados que obtiveram algum valor de fato, a maioria destes apresentou cumprimento de itens de informação tanto técnicos (como atualização, autenticidade, integridade, primariedade, tecnologia, estrutura e disponibilização de documentos em formatos acessíveis) quanto de conteúdo informacional (junto ao uso de linguagem verbal de fácil compreensão).

Tabela 7 - Ranking de transparência da informação complementar secundária

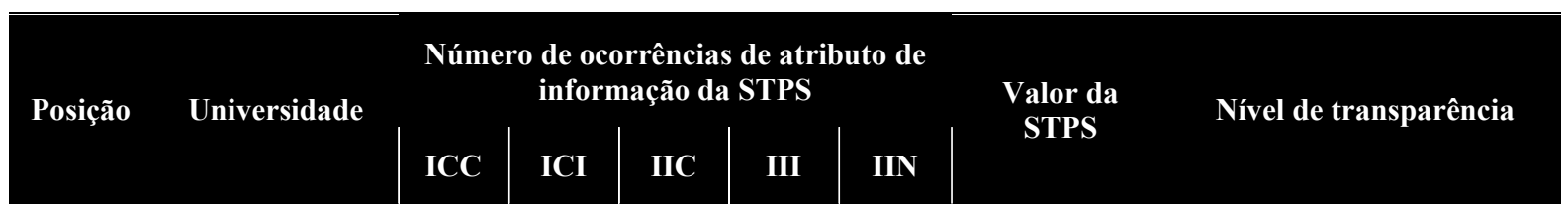




\begin{tabular}{|c|c|c|c|c|c|c|c|c|}
\hline $1^{\mathrm{a}}$ & UFV & - & - & 9 & - & 1 & $\mathbf{0 , 4 5 0}(45 \%)$ & Transparência moderada \\
\hline $1^{\mathrm{a}}$ & UFJF & - & - & 9 & - & 1 & $\mathbf{0 , 4 5 0}(45 \%)$ & Transparência moderada \\
\hline $2^{\mathrm{a}}$ & UFU & - & 1 & 7 & - & 2 & $\mathbf{0 , 4 2 5}(42,50 \%)$ & Transparência moderada \\
\hline $3^{\mathrm{a}}$ & UFRPE & - & - & 8 & - & 2 & $\mathbf{0 , 4 0 0}(40 \%)$ & Transparência frágil \\
\hline $4^{\mathrm{a}}$ & UFABC & - & - & 7 & - & 3 & $\mathbf{0 , 3 5 0}(35 \%)$ & Transparência frágil \\
\hline $4^{\mathrm{a}}$ & UFSCAR & - & - & 7 & - & 3 & $\mathbf{0 , 3 5 0}(35 \%)$ & Transparência frágil \\
\hline $4^{a}$ & UFRN & - & - & 7 & - & 3 & $\mathbf{0 , 3 5 0}(35 \%)$ & Transparência frágil \\
\hline $5^{\mathrm{a}}$ & UFC & - & - & 6 & 2 & 2 & $\mathbf{0 , 3 5 0}(35 \%)$ & Transparência frágil \\
\hline $6^{\mathrm{a}}$ & UFBA & - & - & 6 & - & 4 & $\mathbf{0 , 3 0 0}(35 \%)$ & Transparência frágil \\
\hline $6^{\mathrm{a}}$ & UFG & - & - & 6 & - & 4 & $\mathbf{0 , 3 0 0}(30 \%)$ & Transparência frágil \\
\hline $6^{\mathrm{a}}$ & UFMG & - & - & 6 & - & 4 & $\mathbf{0 , 3 0 0}(30 \%)$ & Transparência frágil \\
\hline $6^{\mathrm{a}}$ & UFPE & - & - & 6 & - & 4 & $\mathbf{0 , 3 0 0}(30 \%)$ & Transparência frágil \\
\hline $6^{\mathrm{a}}$ & UFRJ & - & - & 6 & - & 4 & $\mathbf{0 , 3 0 0}(30 \%)$ & Transparência frágil \\
\hline $6^{\mathrm{a}}$ & UFSC & - & - & 6 & - & 4 & $\mathbf{0 , 3 0 0}(30 \%)$ & Transparência frágil \\
\hline $7^{\mathrm{a}}$ & UNIFESP & - & - & 5 & 1 & 4 & $\mathbf{0 , 2 7 5}(27,5 \%)$ & Transparência frágil \\
\hline $8^{\mathrm{a}}$ & UFLA & - & - & 5 & - & 5 & $\mathbf{0 , 2 5 0}(25 \%)$ & Transparência frágil \\
\hline $8^{\mathrm{a}}$ & UFSM & - & - & 5 & - & 5 & $\mathbf{0 , 2 5 0}(25 \%)$ & Transparência frágil \\
\hline $9^{\mathrm{a}}$ & UNB & - & - & 2 & 5 & 3 & $\mathbf{0 , 2 2 5}(22,50 \%)$ & Transparência frágil \\
\hline $10^{\mathrm{a}}$ & UFPR & - & - & 4 & - & 6 & $\mathbf{0 , 2 0 0}(20 \%)$ & Transparência mínima \\
\hline $11^{\mathrm{a}}$ & UFRGS & - & - & - & 3 & 7 & $\mathbf{0 , 0 7 5}(7,5 \%)$ & Transparência mínima \\
\hline
\end{tabular}

Fonte: elaborada pelos autores.

Diante da Tabela 7, observam-se níveis variados de transparência da informação complementar secundária referentes aos sítios da amostra, sendo que três (3) deles (UFV, UFJF e UFU) situaram-se no nível de "transparência moderada", apresentando um bom desempenho; quinze (15) deles (UFRPE, UFABC, UFSCAR, UFRN, UFC, UFBA, UFG, UFMG, UFPE, UFRJ, UFSC, UNIFESP, UFLA, UFSM e UNB), no nível de "transparência frágil”; e os dois (2) restantes (UFPR e UFRGS), no nível de "transparência mínima”.

Logo, os sítios que apresentaram o maior nível de transparência da informação complementar secundária foram os da UFV e UFJF ("transparência moderada"), empatados com o valor 0,450 ( $45 \%$ do valor total da STPS). Por outro lado, o sítio que apresentou o menor nível de transparência da informação complementar secundária foi o da UFRGS 
("transparência mínima"), com o valor 0,075 (7,5\% do valor total da STPS), destacando-se negativamente pelo alto número de ocorrências do atributo IIN (7 vezes).

Dessa forma, os seguintes sítios eletrônicos podem ser considerados benchmarks para os demais da amostra, visando à busca por uma informação completa e compreensível, no que se refere à transparência da informação complementar secundária:

1) UFV e UFJF (empatados na $1^{\mathrm{a}}$ posição do ranking de transparência da informação complementar secundária), pois, além da obtenção do menor número de ocorrências do atributo IIN (1 vez cada), ainda obtiveram o maior número de ocorrências do atributo IIC (9 vezes cada). Assim, os quesitos verificados que obtiveram algum valor de fato apresentaram informação mais compreensível do que completa, ou seja, com maior cumprimento de itens relativos ao conteúdo informacional aliados ao uso de linguagem verbal de fácil compreensão;

E 2) UFU ( $2^{\mathrm{a}}$ posição do ranking de transparência da informação complementar secundária), pois foi o único sítio a obter o atributo ICI (1 vez), ou seja, o sítio mais próximo de obter o VMQ (o atributo ICC). Assim, conseguiu apresentar um equilíbrio entre informação completa e compreensível, ou seja, os quesitos verificados que obtiveram algum valor de fato apresentaram o cumprimento distribuído de itens de informação tanto técnicos (como atualização, autenticidade, integridade, primariedade, tecnologia, estrutura e disponibilização de documentos em formatos acessíveis) quanto de conteúdo informacional (junto ao uso de linguagem verbal de fácil compreensão).

Tabela 8 - Ranking de transparência da informação total

\begin{tabular}{|c|c|c|c|c|c|c|c|c|c|c|c|}
\hline \multirow{2}{*}{ Posição } & \multirow{2}{*}{ Universidade } & \multicolumn{5}{|c|}{$\begin{array}{l}\text { Número total de ocorrências de } \\
\text { atributo de informação }\end{array}$} & \multicolumn{4}{|c|}{ Valor da dimensão } & \multirow{2}{*}{$\begin{array}{c}\text { Nível de } \\
\text { transparência da } \\
\text { informação total }\end{array}$} \\
\hline & & ICC & ICI & IIC & III & IIN & STA & STPP & STPS & STG (\%) & \\
\hline $1^{\mathrm{a}}$ & UFABC & - & 1 & 31 & 17 & 13 & 2,535 & 0,500 & 0,350 & $\begin{array}{c}\mathbf{3 , 3 8 5} \\
(33,85 \%)\end{array}$ & Transparência frágil \\
\hline $2^{a}$ & UFRJ & - & - & 31 & 17 & 14 & 2,340 & 0,562 & 0,300 & $\begin{array}{c}\mathbf{3 , 2 0 2} \\
(32,02 \%)\end{array}$ & Transparência frágil \\
\hline $3^{\mathrm{a}}$ & UFU & 1 & 6 & 24 & 10 & 21 & 1,950 & 0,718 & 0,425 & $\begin{array}{c}\mathbf{3 , 0 9 3} \\
(30,93 \%)\end{array}$ & Transparência frágil \\
\hline $4^{a}$ & UFLA & - & - & 29 & 16 & 17 & 2,291 & 0,531 & 0,250 & $\begin{array}{c}\mathbf{3 , 0 7 2} \\
(30,72 \%)\end{array}$ & Transparência frágil \\
\hline $5^{\mathrm{a}}$ & UFPE & - & - & 33 & 8 & 21 & 1,852 & 0,750 & 0,300 & $\begin{array}{c}\mathbf{2 , 9 0 2} \\
(29,02 \%)\end{array}$ & Transparência frágil \\
\hline $6^{\mathrm{a}}$ & UFSM & - & 1 & 30 & 7 & 24 & 2,047 & 0,562 & 0,250 & $\begin{array}{c}\mathbf{2 , 8 5 9} \\
(28,59 \%)\end{array}$ & Transparência frágil \\
\hline
\end{tabular}




\begin{tabular}{|c|c|c|c|c|c|c|c|c|c|c|c|}
\hline $7^{\mathrm{a}}$ & UFSCAR & - & 1 & 29 & 8 & 24 & 1,998 & 0,437 & 0,350 & $\begin{array}{c}\mathbf{2 , 7 8 5} \\
(27,85 \%)\end{array}$ & Transparência frágil \\
\hline $8^{\mathrm{a}}$ & UFC & - & - & 23 & 20 & 19 & 2,145 & 0,250 & 0,350 & $\begin{array}{c}\mathbf{2 , 7 4 5} \\
(27,45 \%)\end{array}$ & Transparência frágil \\
\hline $9^{a}$ & UFG & - & - & 26 & 9 & 27 & 1,901 & 0,312 & 0,300 & $\begin{array}{c}\mathbf{2 , 5 1 3} \\
(25,13 \%)\end{array}$ & Transparência frágil \\
\hline $10^{\mathrm{a}}$ & UFSC & - & - & 26 & 11 & 25 & 1,706 & 0,500 & 0,300 & $\begin{array}{c}\mathbf{2 , 5 0 6} \\
(25,06 \%)\end{array}$ & Transparência frágil \\
\hline $11^{\mathrm{a}}$ & UFV & - & - & 25 & 11 & 26 & 1,657 & 0,281 & 0,450 & $\begin{array}{c}\mathbf{2 , 3 8 8} \\
(23,88 \%)\end{array}$ & Transparência frágil \\
\hline $12^{\mathrm{a}}$ & UFJF & - & 1 & 24 & 9 & 28 & 1,413 & 0,406 & 0,450 & $\begin{array}{c}\mathbf{2 , 2 7 0} \\
(22,70 \%)\end{array}$ & Transparência frágil \\
\hline $13^{\mathrm{a}}$ & UFPR & - & - & 23 & 9 & 30 & 1,657 & 0,406 & 0,200 & $\begin{array}{c}\mathbf{2 , 2 6 3} \\
(22,63 \%)\end{array}$ & Transparência frágil \\
\hline $14^{\mathrm{a}}$ & UFBA & - & 1 & 21 & 10 & 30 & 1,706 & 0,250 & 0,300 & $\begin{array}{c}\mathbf{2 , 2 5 6} \\
(22,56 \%)\end{array}$ & Transparência frágil \\
\hline $15^{\mathrm{a}}$ & UNIFESP & - & - & 19 & 18 & 25 & 1,462 & 0,468 & 0,275 & $\begin{array}{c}\mathbf{2 , 2 0 5} \\
(22,05 \%)\end{array}$ & Transparência frágil \\
\hline $16^{\mathrm{a}}$ & UNB & - & 1 & 13 & 25 & 23 & 1,560 & 0,406 & 0,225 & $\begin{array}{c}\mathbf{2 , 1 9 1} \\
(21,91 \%)\end{array}$ & Transparência frágil \\
\hline $17^{\mathrm{a}}$ & UFRN & - & - & 26 & 6 & 30 & 1,267 & 0,531 & 0,350 & $\begin{array}{c}\mathbf{2 , 1 4 8} \\
(21,48 \%)\end{array}$ & Transparência frágil \\
\hline $18^{\mathrm{a}}$ & UFRPE & - & - & 22 & 11 & 29 & 1,218 & 0,437 & 0,400 & $\begin{array}{c}\mathbf{2 , 0 5 5} \\
(20,55 \%)\end{array}$ & Transparência frágil \\
\hline $19^{\mathrm{a}}$ & UFMG & - & - & 16 & 10 & 36 & 1,121 & 0,218 & 0,300 & $\begin{array}{c}\mathbf{1 , 6 3 9} \\
(16,39 \%)\end{array}$ & Transparência mínima \\
\hline $20^{\mathrm{a}}$ & UFRGS & - & - & 6 & 21 & 35 & 1,023 & 0,281 & 0,075 & $\begin{array}{c}\mathbf{1 , 3 7 9} \\
(13,79 \%)\end{array}$ & Transparência mínima \\
\hline
\end{tabular}

Fonte: elaborada pelos autores.

Diante da Tabela 8, observam-se baixos níveis de transparência da informação total relativa aos sítios da amostra, sendo que dezoito (18) deles (UFABC, UFRJ, UFU, UFLA, UFPE, UFSM, UFSCAR, UFC, UFG, UFSC, UFV, UFJF, UFPR, UFBA, UNIFESP, UNB, UFRN e UFRPE) se situaram no nível de "transparência frágil", e os dois (2) restantes (UFMG e UFRGS), no nível de "transparência mínima".

Logo, o sítio que apresentou o maior nível de transparência da informação total foi o da UFABC ("transparência frágil"), com o valor 3,385 (33,85\% do valor total da STG). Por outro lado, os sítios que apresentaram os menores níveis de transparência da informação total foram os da UFMG ("transparência mínima"), com o valor 1,639 (16,39\% do valor total da STG), e UFRGS ("transparência mínima", com o valor 1,379 (13,79\% do valor total da STG), por isso obtiveram os piores desempenhos deste ranking, fundamentalmente em 
virtude das maiores incidências do atributo IIN dentre os demais sítios, sendo 36 vezes para o primeiro e 35 vezes para o segundo.

Dessa forma, os seguintes sítios eletrônicos podem ser considerados benchmarks para os demais da amostra, visando à busca por uma informação completa e compreensível, no que se refere à transparência da informação total:

1) UFABC ( $\left(1^{a}\right.$ posição do ranking de transparência da informação total), pois, além da obtenção do menor número de ocorrências do atributo IIN (13 vezes), ainda obteve o segundo maior número de ocorrências do atributo IIC (31 vezes) e está dentre os sete sítios que obtiveram o atributo ICI (ao menos 1 vez). Assim, dos quesitos verificados que obtiveram algum valor de fato, a maioria apresentou informação mais compreensível do que completa, ou seja, com maior cumprimento de itens relativos ao conteúdo informacional aliados ao uso de linguagem verbal de fácil compreensão;

2) UFU ( $3^{\mathrm{a}}$ posição do ranking de transparência da informação total), pois foi o sítio que mais obteve o atributo IIC (6 vezes) e o único a obter o VMQ (o atributo ICI por 1 vez). Assim, foi o único sítio que conseguiu apresentar um equilíbrio entre informação completa e compreensível, ou seja, os quesitos verificados que obtiveram algum valor de fato apresentaram cumprimento de itens de informação tanto técnicos (como atualização, autenticidade, integridade, primariedade, tecnologia, estrutura e disponibilização de documentos em formatos acessíveis) quanto de conteúdo informacional (junto ao uso de linguagem verbal de fácil compreensão);

E 3) UFPE ( $5^{\text {a }}$ posição do ranking de transparência da informação total), pois foi o sítio que obteve o maior número de ocorrências do atributo IIC (33 vezes). Assim, dos quesitos verificados que obtiveram algum valor de fato, a maioria apresentou informação mais compreensível do que completa, ou seja, com maior cumprimento de itens relativos ao conteúdo informacional aliados ao uso de linguagem verbal de fácil compreensão.

\section{CONSIDERAÇÕES FINAIS}

Historicamente, o estabelecimento de uma relação de credibilidade e boa-interação entre Estado e sociedade civil tem se subordinado, imprescindivelmente, à transparência das ações da AP. Com base nisso, em combate permanente à corrupção e visando ao aprimoramento da democracia, representada por uma gestão pública voltada ao atendimento às diversas, sucessivas, contingentes e complexas demandas sociais, o acesso à informação pública tem se tornado pauta cada vez mais relevante mundialmente (ROSA et al., 2016). 
No Brasil, a regulação do acesso à informação pública é bastante recente (efetivamente desde 2012), mediante a LAI (BRASIL, 2011), que passou a representar oficialmente a materialização dos direitos universal e constitucional à informação pública e a reafirmação da prática de transparência como um subsídio aos exercícios da participação e do controle sociais. A efetividade destes exercícios, no entanto, está condicionada determinantemente à qualidade do acesso por meio do qual o cidadão toma ciência e compreensão das ações da AP (BITENCOURT; RECK, 2016).

Nesse raciocínio, se as informações disponíveis em sítios público-eletrônicos do país ("transparência ativa") estão indisponíveis, incompletas e/ou incompreensíveis, elas podem comprometer o cumprimento factual da LAI e a promoção de transparência num todo. Assim sendo, buscou-se responder à seguinte questão: com base na LAI, como se mensurar a qualidade da informação disponível nos sítios eletrônicos de universidades federais do Brasil?

Sabendo-se que, de acordo com a LAI (BRASIL, 2011, art. $5^{\circ}$, grifo nosso), “é dever do Estado garantir o direito de acesso à informação [...] de forma transparente, clara e em linguagem de fácil compreensão", para se responder à pergunta-problema, foi proposto o desenvolvimento do IBTIPE, definido como um índice bidimensional de transparência verificável a partir de uma checklist qualitativa da informação disponível em sítios públicoeletrônicos do PEF (especificamente os de universidades federais do Brasil).

A partir da apresentação do método do instrumento proposto, entende-se que o objetivo (principal contributo) desta pesquisa foi cumprido, tendo-se pretendido elevar a noção teórica de "qualidade da informação" a um patamar de conceito que alinhasse o conteúdo informacional de cada quesito proposto a aspectos técnico-informacionais.

Isso possibilitou mensurar, de forma mais precisa possível, a qualidade da informação disponível nos sítios eletrônicos de universidades federais brasileiras, tornando, assim, exequíveis as finalidades propostas pelo IBTIPE de se: mensurar os níveis de cumprimento factual da LAI e de transparência das informações complementar e total relativos a esses sítios; e elaborar rankings referentes a esses níveis.

Em consideração à coleta dos dados, é relevante destacar uma limitação desta pesquisa: os dados disponíveis nos sítios possuem uma natureza efêmera, podendo ser editados pelo servidor público responsável sem aviso prévio, o que pode impactar o valor de um determinado quesito e, logo, o valor final de uma dimensão de transparência. Assim, há que se esclarecer que os resultados do IBTIPE obtidos por cada sítio da amostra se limitaram 
ao dia e, mais especificamente, ao período de tempo (individual) de realização da coleta de dados.

Ainda quanto à coleta dos dados, corroborando-se as considerações dos estudos de Raupp e Pinho (2014), Moraes Junior, Carneiro e Silva Neto (2015), Raupp e Pinho (2015), Amorim e Almada (2016), Jahns e Raupp (2016), Andrade e Raupp (2017) e Andrade, Raupp e Pinho (2017), constatou-se uma dificuldade na localização das informações, em razão dos vários tipos de layout apresentados pelos sítios, excetuando-se cinco (5) destes (UFABC, UFLA, UFSC, UFSM e UFU), que buscaram se assemelhar visualmente a sítios da alta AP do país. Logo, entende-se que, conquanto a padronização de layout não seja um quesito obrigatório pela LAI (salvo alguns itens tecnológico-estruturais), poderia ser um componente relevante ao acesso eficiente da informação público-eletrônica.

No que concerne aos principais resultados desta pesquisa, diante da apresentação dos rankings relativos às dimensões de transparência dos sítios da amostra, foram identificados:

- Melhores sítios referentes ao cumprimento factual da LAI (UFABC), à transparência da informação complementar primária (UFPE), à transparência da informação complementar secundária (UFV e UFJF) e à transparência da informação total (UFABC);

- Piores sítios referentes ao cumprimento factual da LAI (UFRGS), à transparência da informação complementar primária (UFMG), à transparência da informação complementar secundária (UFRGS) e à transparência da informação total (UFRGS);

- Benchmarks, visando à busca por uma informação completa e compreensível, referentes ao cumprimento factual da LAI (UFABC, UFRJ e UFU), à transparência da informação complementar primária (UFPE e UFU), à transparência da informação complementar secundária (UFV, UFJF e UFU) e à transparência da informação total (UFABC, UFU e UFPE).

Apesar desses resultados, todos os sítios da amostra apresentaram baixos desempenhos em todas as dimensões de transparência (STA, STPP, STPS e STG) - à exceção do bom desempenho dos sítios da UFV, UFJF e UFU obtido com relação à transparência da informação complementar secundária ("transparência moderada") - o que, por outro lado, realçou a proposta do IBTIPE de maximizar a precisão da qualidade da informação.

Nesse contexto e reafirmando-se os estudos de Silva e Carreiro (2013), Raupp e Pinho (2014), Moraes Junior, Carneiro e Silva Neto (2015), Raupp e Pinho (2015), Albuquerque e Hermida (2016), Andrade e Raupp (2017) e Andrade, Raupp e Pinho (2017), a verificação dessa qualidade se traduziu pouco satisfatória (ou pouco transparente) num todo, para uma 
verdadeira ciência/compreensão/confiança pelo cidadão, ora mostrando-se pouco completa, ora pouco compreensível.

Mais especificamente, verificaram-se altas ocorrências de atributos, sobretudo, de médio para baixo valor (IIC e IIC) e sem valor (IIN), justificadas por duas formas de disponibilização da informação observadas: 1) forma irregular - o cumprimento de um item técnico ("atualização" por exemplo) num determinado quesito e, ao mesmo tempo, o descumprimento do mesmo item em outro quesito, e/ou a presença do link de um determinado quesito, mas sem conteúdo algum; e 2) forma desordenada/sem padrão informação fora do local exigido e/ou informação inexistente (sem link).

Quanto a esta última característica observada, a verificação de ausência total do eixo "Participação Social" em catorze (14) sítios da amostra e de sua ausência parcial em até dezessete (17) sítios revelou uma preocupação em vista da obrigatoriedade da LAI e, ao mesmo tempo, uma incoerência dado que um dos propósitos desta legislação é justamente a promoção de participação social (por lógica, um dos principais eixos temáticos), mas que não teve a devida atenção pela maioria dos sítios.

Com base na observação dessas características, é possível afirmar, no caso do cumprimento factual da LAI, que a maioria dos sítios não vinha seguindo fielmente as orientações do Guia de Transparência Ativa para Órgãos e Entidades do Poder Executivo Federal (BRASIL, 2017a), do e-MAG (BRASIL, 2014) e da própria LAI, demonstrando pouco engajamento por parte dos agentes públicos das universidades federais da amostra para cumprir corretamente a lei (ou, ao menos, apresentar um bom nível de cumprimento) e podendo justificar, em parte, o crescente número de solicitações de informação realizadas pelo usuário-cidadão via SIC desde a instituição da LAI.

Por outro lado, os discentes das universidades federais da amostra (como os maiores afetados no âmbito destas instituições) e os principais stakeholders externos (MEC, CGU, TCU e CAPES) aparentemente não têm mostrado sinergia para exercer o devido controle social com relação aos sítios dessas universidades, devendo colocar mais rigor na prática da accountability, ao cobrar mais efetivamente o cumprimento da LAI por estas e, em caso contrário, a aplicação de penalidades.

Assim, em se tratando do tema "transparência" de forma mais ampla, a criação de um instrumento confiável que possa verificar com alta precisão a qualidade da informação disponível em sítios público-eletrônicos (e, logo, o cumprimento factual da LAI e a transparência num todo) tal qual proposto por este estudo por meio do IBTIPE não se configura numa solução-fim à efetividade de políticas públicas, mas sim uma solução-meio. 
Tornam-se inevitáveis, portanto, a conscientização, a união e a atuação dos cidadãos e de toda a AP em prol de divulgar/praticar permanentemente a cultura da transparência em todos os segmentos da sociedade, como um fator preponderante para a evolução do acesso à informação no Brasil e, intrinsecamente, da participação e do controle sociais.

Visando a futuros estudos, sugerem-se, com base na linha temática deste trabalho: 1) a repetição do presente estudo, ampliando-se os objetos de estudo para os sítios eletrônicos de todas as universidades federais brasileiras; e 2) a verificação da relação entre a transparência desses sítios e o orçamento anual recebido pelas universidades federais brasileiras.

\section{REFERÊNCIAS}

ABDALA, P. R. Z.; TORRES, C. M. S. de O e. A transparência como espetáculo: uma análise dos portais de transparência de estados brasileiros. Administração Pública e Gestão Social, Viçosa, MG, v. 8, n. 3, p. 147-158, jul./set. 2016. DOI:

https://doi.org/10.21118/apgs.v1i3.1023.

AKUTSU, L.; PINHO, J. A. G. de. Sociedade da informação, accountability e democracia delegativa: investigação em portais de governo no Brasil. Revista de Administração

Pública, Rio de Janeiro, RJ, v. 36, n. 5, p. 723-745, set./out. 2002. Disponível em:

http://bibliotecadigital.fgv.br/ojs/index.php/rap/article/view/6461/5045. Acesso em: 25 ago. 2018.

ALBUQUERQUE, B. M.; SILVA, F. C. A. da; SOUSA, T. P. de. A era eletrônica da Administração Pública Federal: desafios e evolução no cenário brasileiro. Vianna Sapiens, Juiz de Fora, MG, v. 8, n. 2, p. 340-358, jul./dez. 2017. DOI:

https://doi.org/10.31994/rvs.v8i2.245.

ALBUQUERQUE, E. F.; HERMIDA, J. F. Portais da transparência como instrumentos de controle social na Paraíba (2009-2013). Gestão \& Aprendizagem, João Pessoa, PB, v. 5, n. 2, p. 180-201, 2016. DOI: https://doi.org/10.23179/g\&a.v5i2.32310.

AMORIM, P. K.; ALMADA, M. P. E-transparência: proposta de modelo metodológico para avaliação de portais de Executivos nacionais. Logos - Comunicação e Universidade, Rio de Janeiro, RJ, v. 23, n. 2, p. 54-67, 2016. DOI: https://doi.org/10.12957/logos.2016.19601. ANDRADE, R. G. de; RAUPP, F. M. Transparência do Legislativo local à luz da Lei de Acesso à Informação: evidências empíricas a partir dos maiores municípios brasileiros.

Desenvolvimento em Questão, Ijuí, RS, v. 15, n. 41, p. 85-130, out. 2017. DOI:

https://doi.org/10.21527/2237-6453.2017.41.85-130. 
ANDRADE, R. G. de; RAUPP, F. M; PINHO, J. A. G. de. Em busca da transparência ativa em câmaras: uma investigação nos maiores municípios brasileiros. Advances in Scientific and Applied Accounting, São Paulo, SP, v. 10, n. 1, p. 3-20, jan./abr. 2017. DOI: http://dx.doi.org/10.14392/asaa.2017100101.

BITENCOURT, C. M.; RECK, J. R. Controle da transparência na contratação pública no Brasil - o acesso à informação como forma de viabilizar o controle social da Administração Pública. Revista do Direito, Santa Cruz do Sul, RS, v. 2, n. 49, p. 96-115, mai./ago. 2016. DOI: http://dx.doi.org/10.17058/rdunisc.v2i49.7892.

BRASIL. Acesso à Informação. Guia de Transparência Ativa para Órgãos e Entidades do Poder Executivo Federal. 5. versão. 2017. Disponível em:

http://www.acessoainformacao.gov.br/lai-para-sic/sic-apoio-orientacoes/guias-eorientacoes/gta-5a-versao.pdf. Acesso em: 7 jun. 2018.

BRASIL. E-SIC - Sistema Eletrônico do Serviço de Informação ao Cidadão. Relatórios Estatísticos. 2018. Disponível em:

https://esic.cgu.gov.br/sistema/Relatorios/Anual/RelatorioAnualPedidos.aspx. Acesso em: 3 jan. 2019.

BRASIL. Instituto Nacional de Estudos e Pesquisas Educacionais Anísio Teixeira. Índice Geral de Cursos. 2017. Disponível em:

http://download.inep.gov.br/educacao_superior/igc_cpc/2018/resultado_igc_2017.xlsx. Acesso em: 31 dez. 2018.

BRASIL. Instituto Nacional de Estudos e Pesquisas Educacionais Anísio Teixeira. Sinopses estatísticas da Educação Superior. 2016. Disponível em:

http://portal.inep.gov.br/web/guest/sinopses-estatisticas-da-educacao-superior. Acesso em: 12 jun. 2018.

BRASIL. Ministério da Transparência e Controladoria-Geral da União. Escala Brasil Transparente. 2018. Disponível em: http://www.cgu.gov.br/assuntos/transparenciapublica/escala-brasil-transparente. Acesso em: $31 \mathrm{dez} .2018$.

BRASIL. Secretaria de Logística e Tecnologia da Informação. E-MAG - Modelo de Acessibilidade em Governo Eletrônico. Brasília, DF: MP; SLTI, 2014. 92 p. color.

Disponível em: https://www.governodigital.gov.br/documentos-e-arquivos/eMAGv31.pdf. Acesso em: 11 jun. 2018.

BRASIL. Subchefia para Assuntos Jurídicos. Constituição da República Federativa do Brasil de 1988. Disponível em:

http://www.planalto.gov.br/ccivil_03/constituicao/constituicao.htm. Acesso em: 5 jun. 2018. 
BRASIL. Decreto no 592, de 6 de julho de 1992. Atos Internacionais. Pacto Internacional sobre Direitos Civis e Políticos. Promulgação. Disponível em: http://www.planalto.gov.br/ccivil_03/decreto/1990-1994/d0592.htm. Acesso em: 21 jun. 2018 .

BRASIL. Decreto n ${ }^{0}$ 5.687, de 31 de janeiro de 2006. Promulga a Convenção das Nações Unidas contra a Corrupção, adotada pela Assembleia-Geral das Nações Unidas em 31 de outubro de 2003 e assinada pelo Brasil em 9 de dezembro de 2003. Disponível em: http://www.planalto.gov.br/ccivil_03/_ato2004-2006/2006/decreto/d5687.htm. Acesso em: 21 jun. 2018.

BRASIL. Decreto $\mathbf{n}^{\mathbf{0}} \mathbf{7 . 7 2 4}$, de 16 de maio de 2012. Regulamenta a Lei $\mathrm{n}^{\mathbf{0}} 12.527$, de 18 de novembro de 2011, que dispõe sobre o acesso a informações previsto $\mathrm{n}^{\circ}$ inciso XXXIII do caput do art. $5^{\circ}$, no inciso II do $\S 3^{\circ}$ do art. $37^{\circ}$ e no $\S 2^{\circ}$ do art. $216^{\circ}$ da Constituição.

Disponível em: http://www.planalto.gov.br/ccivil_03/_ato2011-

2014/2012/decreto/d7724.htm. Acesso em: 5 jun. 2018.

BRASIL. Lei complementar $n^{0} 101$, de 4 de maio de 2000. Estabelece normas de finanças públicas voltadas para a responsabilidade na gestão fiscal e dá outras providências.

Disponível em: http://www.planalto.gov.br/ccivil 03/Leis/lcp/Lcp101.htm. Acesso em: 5 jun. 2018.

BRASIL. Lei complementar $\mathbf{n}^{0}$ 131, de 27 de maio de 2009. Acrescenta dispositivos à Lei Complementar $\mathrm{n}^{\mathrm{o}} 101$, de 4 de maio de 2000, que estabelece normas de finanças públicas voltadas para a responsabilidade na gestão fiscal e dá outras providências, a fim de determinar a disponibilização, em tempo real, de informações pormenorizadas sobre a execução orçamentária e financeira da União, dos Estados, do Distrito Federal e dos Municípios. Disponível em: http://www.planalto.gov.br/ccivil_03/Leis/LCP/Lcp131.htm. Acesso em: 5 jun. 2018.

BRASIL. Lei no 8.159, de 8 de janeiro de 1991. Dispõe sobre a política nacional de arquivos públicos e privados e dá outras providências. Disponível em:

http://www.planalto.gov.br/ccivil_03/leis/L8159.htm. Acesso em: 15 jun. 2018.

BRASIL. Lei n 9.755, de 16 de dezembro de 1998. Dispõe sobre a criação de "homepage" na "Internet", pelo Tribunal de Contas da União, para divulgação dos dados e informações que especifica, e dá outras providências. Disponível em: http://www.planalto.gov.br/ccivil_03/Leis/L9755.htm. Acesso em: 18 jul. 2018. BRASIL. Lei $\mathbf{n}^{\mathbf{0}}$ 12.527, de 18 de novembro de 2011. Regula o acesso a informações previsto no inciso XXXIII do art. $5^{\circ}$, no inciso II do $\S 3^{\circ}$ do art. $37^{\circ}$ e no $\S 2^{\circ}$ do art. $216^{\circ}$ da 
Constituição Federal; altera a Lei $n^{0}$ 8.112, de 11 de dezembro de 1990; revoga a Lei $\mathrm{n}^{\mathbf{o}}$ 11.111, de 5 de maio de 2005, e dispositivos da Lei $n^{\circ} 8.159$, de 8 de janeiro de 1991; e dá outras providências. Disponível em: http://www.planalto.gov.br/ccivil_03/_ato20112014/2011/lei/112527.htm. Acesso em: 5 jun. 2018.

CALAZANS, A. T. S. Qualidade da informação: conceitos e aplicações. Transinformação, Campinas, SP, v. 20, n. 1, p. 29-45, jan./abr. 2008.

CLÈVE, C. M.; FRANZONI, J. A. Administração Pública e a nova Lei de Acesso à Informação. Interesse Público, Belo Horizonte, MG, v. 15, n. 79, p. 15-40, mai./jun. 2013. Disponível em: http://www.editoraforum.com.br/wp-content/uploads/2013/10/DireitoPublico-Administracao-Publica-e-a-nova-Lei-de-Acesso-a-Informacao.pdf. Acesso em: 27 ago. 2018.

JAHNS, F. T.; RAUPP, F. M. Transparência de informações do Executivo estadual: proposta de ações de melhoria para o portal de Santa Catarina. FACEF Pesquisa: Desenvolvimento e Gestão, Franca, SP, v. 19, n. 1, p. 18-34, jan./abr. 2016. Disponível em: http://periodicos.unifacef.com.br/index.php/facefpesquisa/article/download/1119/960. Acesso em: 27 jul. 2018.

LIKERT, R. A technique for the measurement of attitudes. Archives of Psychology, New York, v. 22, n. 140, p. 5-55, jun. 1932. Disponível em:

https://legacy.voteview.com/pdf/Likert_1932.pdf. Acesso em: 3 set. 2018.

MICHENER, G.; BERSCH, K. Conceptualizing the quality of transparency. Political

Concepts, v. 49, p. 1-27, 2011. Disponível em: http://www.concepts-

methods.org/Files/WorkingPaper/PC 49 Michener_Bersch.pdf. Acesso em: 30 set. 2018.

MORAES JUNIOR, D. N.; CARNEIRO, A. de F.; SILVA NETO, J. M. da. Nível e ranking da transparência e acesso à informação dos municípios de Rondônia. Amazônia,

Organizações e Sustentabilidade, Belém, PA, v. 4, n. 2, p. 47-64, ago./dez. 2015. DOI: http://dx.doi.org/10.17800/2238-8893/aos.v4n2p47-64.

NEHMY, R. M. Q.; PAIM, I. A desconstrução do conceito de "qualidade da informação".

Ciência da Informação, Brasília, DF, v. 27, n. 1, p. 36-45, jan./abr. 1998. DOI:

http://dx.doi.org/10.1590/S0100-19651998000100005.

ORGANIZAÇÃO DAS NAÇÕES UNIDAS. Declaração Universal dos Direitos Humanos.

Rio de Janeiro, RJ: UNIC, 2009. Disponível em:

http://www.onu.org.br/img/2014/09/DUDH.pdf. Acesso em: 5 jun. 2018.

ORGANIZAÇÃO DOS ESTADOS AMERICANOS. Comissão Interamericana de Direitos

Humanos. Declaração de Princípios sobre Liberdade de Expressão. out. 2000. Disponível 
em: https://www.cidh.oas.org/basicos/portugues/s.Convencao.Libertade.de.Expressao.htm. Acesso em: 21 jun. 2018.

PLATT NETO, O. A.; CRUZ, F. da; ENSSLIN, S. R.; ENSSLIN, L. Publicidade e transparência das contas públicas: obrigatoriedade e abrangência desses princípios na Administração Pública brasileira. Contabilidade Vista \& Revista, Belo Horizonte, MG, v. 18, n. 1, p. 75-94, jan./mar. 2007. Disponível em:

https://revistas.face.ufmg.br/index.php/contabilidadevistaerevista/article/view/320/313. Acesso em: 20 jul. 2018.

PRODANOV, C. C.; FREITAS, E. C. de. Metodologia do trabalho científico: métodos e técnicas da pesquisa e do trabalho acadêmico. 2. Ed. Novo Hamburgo, RS: Feevale, 2013. RAUPP, F. M.; PINHO, J. A. G. de. Prestação de contas no Legislativo local antes e depois da Lei de Acesso à Informação. ConTexto, Porto Alegre, RS, v. 15, n. 29, p. 30-46, jan./abr. 2015. Disponível em: https://seer.ufrgs.br/ConTexto/article/view/46219. Acesso em: 25 ago. 2018.

RAUPP, F. M.; PINHO, J. A. G. de. Prestação de contas nos portais eletrônicos de assembleias legislativas: um estudo após a Lei de Acesso à Informação. Revista Gestão e Planejamento, Salvador, BA, v. 15, n. 1, p. 144-161, jan./abr. 2014. Disponível em: https://revistas.unifacs.br/index.php/rgb/article/view/2411. Acesso em: 25 ago. 2018. ROSA, M. M. da; BERNARDO, F. D.; VICENTE, E. F. R.; PETRI, S. M. A Lei de Acesso à Informação como instrumento de controle social: diagnóstico dos municípios do Sul do Brasil à luz do artigo $8^{\circ}$ da Lei 12527/2011. Navus, Florianópolis, SC, v. 6, n. 1, p. 72-87, jan./mar. 2016. DOI: https://doi.org/10.22279/navus.2016.v6n1.p72-87.359.

SILVA, M. P. A. e; CARREIRO, R. A qualidade da informação pública: uma análise do grau de transparência dos portais de cinco estados brasileiros. Comunicologia, Brasília, DF, v. 6, n. 2, p. 3-23, jul./dez. 2013. DOI: http://dx.doi.org/10.24860/comunicologia.v6i2.5276. SILVA, T. E. da; EIRÃO, T. G.; CAVALCANTE, R. S. Acesso à informação: notas de pesquisa. Informação \& Informação, Londrina, PR, v. 18, n. 2, p. 1-19, mai./jul. 2013. DOI: http://dx.doi.org/10.5433/1981-8920.2013v18n2p01.

VALENTE, N. T. Z.; FUJINO, A. Atributos e dimensões de qualidade da informação nas Ciências Contábeis e na Ciência da Informação: um estudo comparativo. Perspectivas em Ciência da Informação, v. 21, n. 2, p. 141-167, abr./jun. 2016. Disponível em: http://portaldeperiodicos.eci.ufmg.br/index.php/pci/article/download/2530/1761. Acesso em: 2 set. 2018. 